\title{
Phagotrophic ciliates and flagellates in an oligotrophic, deep, alpine lake: contrasting variability with seasons and depths
}

\author{
Bettina Sonntag ${ }^{1,2, *}$, Thomas Posch ${ }^{4}$, Susanne Klammer ${ }^{3}$, Katrin Teubner ${ }^{5}$, \\ Roland Psenner ${ }^{2}$ \\ ${ }^{1}$ Laboratory of Aquatic Photobiology \& Plankton Ecology, ${ }^{2}$ Institute of Ecology, and ${ }^{3}$ Institute of Microbiology, \\ Leopold-Franzens-University Innsbruck, Technikerstrasse 25, 6020 Innsbruck, Austria \\ ${ }^{4}$ Limnological Station, Institute of Plant Biology, University of Zürich, Seestraße 187, 8802 Kilchberg, Switzerland \\ ${ }^{5}$ Department Freshwater Ecology, Faculty of Life Sciences, University of Vienna, Althanstrasse 14, 1090 Vienna, Austria
}

\begin{abstract}
We followed the changes in the protist assemblage over an annual cycle at 3 sites and different depths of Traunsee in the Austrian Alps and quantified the variability of the ciliate assemblage along successive depth and time intervals, respectively. More than 60 ciliate species were identified alive and after quantitative protargol staining (QPS). The ciliate diversity was high, and is described in detail for 50 taxa in time-depth intervals. Rimostrombidium brachykinetum/Rimostrombidium hyalinum and Balanion planctonicum were the most frequent species, accounting for $44 \%$ of the annual mean abundance and $15 \%$ of the annual mean biovolume, respectively. Our results suggested a stronger variability in the ciliate assemblage structure within seasons than along the depth gradient. Gradual changes in the assemblage structure with depths: (1) were accompanied by a decrease of algivorous and mixotrophic and an increase of bacterivorous ciliates from surface to deeper layers; (2) were highly significantly altered with steep depth gradients of their potential food resources, i.e. the biomass of heterotrophic flagellates, bacteria and algae; and (3) were related with lower significance to environmental parameters. High similarity $(>80 \%)$ between successive months was reached only when net changes in the total ciliate abundance were negligible, while a strong increase or decrease in the ciliate abundance was associated with pronounced changes in the species composition. These seasonal changes in the ciliate assemblage structure (4) were linked to shifts of algivorous and mixotrophic, but not of bacterivorous ciliates and (5) were less predictable with food resources compared to the depth gradient. The phagotrophic flagellates generally followed the seasonal and vertical patterns described for ciliates, and were shown to be important members of the planktonic food web in a cold, deep, oligotrophic lake.
\end{abstract}

KEY WORDS: Microbial assemblage structure $\cdot$ Functional analysis $\cdot$ Microbial food web $\cdot$ Aquatic protists $\cdot$ Seasonal succession $\cdot$ Ciliate species list

Resale or republication not permitted without written consent of the publisher

\section{INTRODUCTION}

It is well known that protists (unicellular eukaryotes) play a pivotal role in the food web of oceans and lakes (e.g. Azam et al. 1983, Weisse \& Müller 1998). In recent years, knowledge about single ciliate and flagellate species has accumulated, a prerequisite to understanding their contribution and importance to the cycling of carbon and nutrients (see Foissner et al.
1999 and references therein). Nonetheless, reliable data sets on planktonic protistan species are still rare, especially from oligotrophic lakes (Laybourn-Parry 1994, Pfister et al. 2002, Sonntag et al. 2002). In initial studies on planktonic protists, this lack was related to methodological difficulties in the determination of species present at low numbers, i.e. $<1 \mathrm{ml}^{-1}$. This problem, however, has partly been solved by introduction of the Quantitative Protargol Stain (QPS; 
Montagnes \& Lynn 1987, Skibbe 1994), which has been tested for its reliability (Pfister et al. 1999). The microbial community structure in aquatic ecosystems is variable both in time and space; however, few ecological studies have been explicitly devoted to analysis of the magnitude of both kinds of variability operating simultaneously and their underlying causes. In the present study, we focused on 2 major questions. (1) What factors - biotic and/or abiotic - govern the distribution of phagotrophic ciliates and flagellates in the water column of a deep, oligotrophic lake? (2) Does the ciliate assemblage structure correspond to the temporal and spatial distributions of its potential food resources? We interpreted changes in the protist assemblage from high taxonomic and spatial resolution data. According to literature (see below), single ciliate species were categorised according to their prevailing mode of nutrition, i.e. algivorous, mixotrophic, bacterivorous and omnivorous, and were analysed along a time and depth gradient. As potential food sources for the ciliates, we considered chlorophyll $a(\mathrm{chl} a)$, in different size fractions (see below), to be equivalent to autotrophic prey organisms, heterotrophic bacteria and heterotrophic flagellates. Bacteria were considered the main food for phagotrophic flagellates.

\section{MATERIALS AND METHODS}

As the study site (Table 1) and sampling design have already been described in detail (Klammer et al. 2002, Sonntag et al. 2002, Teubner \& Dokulil 2002), we give only brief descriptions.

Investigation site. Traunsee is the second largest and deepest lake situated in the north of the Austrian limestone Alps. The lake has been influenced by the discharge from salt and soda industries for almost 100 yr. A study was carried out to investigate the impact of these wastes on organisms (Schmidt et al. 2002 and references therein). Results have shown that Traunsee receives 135000 tons of alkaline and saline industrial waste per year (Jagsch et al. 2002, Müller et al. 2002). The dissolved salts are mixed with lake water, with maximum concentrations in the hypolimnion, whereas solids are deposited in the southern part of the lake and have, in the meantime, covered $\sim 20 \%$ of the lake bottom via turbidity currents (Müller et al. 2002). Benthic microorganisms in this southern part of Traunsee are heavily affected by their alkaline environment ( $\mathrm{pH}>9$ in the pore water), e.g. bacterial abundance and biomass have been reduced by a factor of 10 compared to undisturbed sediment areas (Griebler et al. 2002). Several publications on the lake have focused on the effect of pollution from salt and soda industries and described, for example, microbial activities such as primary and bacterial production (Griebler et al. 2002, Klammer et al. 2002, Schmidt et al. 2002, Sonntag et al. 2002, Teubner \& Dokulil 2002, Teubner 2003).

Monthly samples taken from November 1997 to October 1998 were analysed at 3 sites selected for a reference study on the microbial community with respect to the disposal of alkaline wastes (sampling map in Sonntag et al. 2002): (1) Viechtau (VI; the reference site at a maximum depth of $191 \mathrm{~m})$, (2) Ebensee Bay $(E B$; the site of industrial waste release; depth $50 \mathrm{~m}$ ), and (3) Rindbach Bay ( $\mathrm{RB}_{\text {; }}$ unpolluted area, influenced by allochthonous material from the main tributary, the Traun River; depth $50 \mathrm{~m}$ ). Sampling depths were $0,10,20,40 \mathrm{~m}$ at the 3 sites, and, additionally, 60, 80, 120 and $160 \mathrm{~m}$ at VI. Throughout the investigation period, Traunsee had a fully oxygenated water column down to the maximum depth $(191 \mathrm{~m})$ and increased chloride accumulation with depth. The lake is holomictic, and mixis occurred in February/March 1998.

Sample treatments and statistics. Oxygen, $\mathrm{pH}$, conductivity, temperature and underwater light were measured immediately after sampling by sensors (WTW) and in situ by a profiler (multi-parameter profiler YSI 6920, $4 \pi$ quantum sensor, LI-COR). Protocols

Table 1. Hydrological, morphometric and physico-chemical parameters of Traunsee. Temperature (T), $\mathrm{pH}, \mathrm{O}_{2}$, conductivity, chloride concentrations, total phosphorus (TP), chlorophyll $a(\mathrm{chl} a)$, mixing depth $\left(z_{\text {mix }}\right)$ and euphotic zone $\left(z_{\text {eu }}\right)$ are averages for the period November 1997 to October 1998, if not otherwise stated (modified from Pechlaner \& Sossau 1982, Sonntag et al. 2002, Teubner \& Dokulil 2002, Teubner 2003). Annual means are given with minimum and maximum values in brackets

\begin{tabular}{|c|c|}
\hline Latitude & $47^{\circ} 48^{\prime}$ to $47^{\circ} 55^{\prime} \mathrm{N}$ \\
\hline Longitude & $13^{\circ} 46^{\prime}$ to $13^{\circ} 49^{\prime} \mathrm{E}$ \\
\hline Altitude (m a.s.l.) & 422 \\
\hline Volume $\left(10^{9} \mathrm{~m}^{3}\right)$ & 2.3 \\
\hline Lake surface area $\left(\mathrm{km}^{2}\right)$ & 24.4 \\
\hline Catchment area $\left(\mathrm{km}^{2}\right)$ & 1417 \\
\hline Maximum length (km) & 12.2 \\
\hline Maximum width $(\mathrm{km})$ & 2.9 \\
\hline Maximum depth (m) & 191 \\
\hline Mean depth (m) & 95 \\
\hline$z_{\text {mix }}($ Jul-Aug) (m) & 6.8 \\
\hline$z_{\mathrm{eu}}(\mathrm{m})$ & $11.3(7.6-17.6)$ \\
\hline Water renewal time (yr) & 1.04 \\
\hline Average discharge $\left(\mathrm{m}^{3} \mathrm{~s}^{-1}\right)$ & 70 \\
\hline$T\left({ }^{\circ} \mathrm{C}\right)$ & $7.8(4.2-20.2)$ \\
\hline $\mathrm{pH}$ & $8.4(6.9-9.8)$ \\
\hline $\mathrm{O}_{2}\left(\mathrm{mg} \mathrm{l}^{-1}\right)$ & $10.6(7.3-15.0)$ \\
\hline Conductivity $\left(\mu \mathrm{S} \mathrm{cm}^{-1}\right)$ & $536(272-840)$ \\
\hline Chloride $\left(\mathrm{mg} \mathrm{l}^{-1}\right)$ & $95(46-172)$ \\
\hline $\mathrm{TP}\left(\mu \mathrm{gl}^{-1}\right)$ & $7.7(4-13.2)$ \\
\hline Chl a $(0-40 \mathrm{~m})\left(\mathrm{gg}^{-1}\right)$ & $1.04(0.14-3.3)$ \\
\hline
\end{tabular}


for the measurements of concentrations of chloride, total phosphorus, chlorophyll, phytoplankton composition and bacterial parameters are described in Griebler et al. (2002), Klammer et al. (2002), Teubner \& Dokulil (2002) and Teubner (2003). Ciliates and flagellates were fixed immediately after sampling with either $5 \%$ Bouin's solution (final concentration) or $2 \%$ formaldehyde (final concentration), respectively. Living ciliates and flagellates were gathered for detailed taxonomic information with a $10 \mu \mathrm{m}$ plankton net and observed within $24 \mathrm{~h}$ after sampling. Subsequently, ciliate samples were stained (with QPS in the modification of Pfister et al. 1999), and flagellates were stained with DAPI (4',6-diamidino-2-phenylindole, Sigma; further details described in Porter \& Feig [1980], Sherr \& Sherr [1993] and Sonntag et al. [2000]). The protists were investigated with a Zeiss Axiophot II microscope (DIC, brightfield, phase contrast, epifluorescence) and identified morphologically after Foissner et al. (1991, 1992, 1994, 1995, 1999) and Patterson \& Larsen (1991 and references therein). The microscopic permanent slides with the QPS-stained ciliates from this investigation were deposited and are available from the Oberösterreichische Landesmuseum in Linz (LI), Austria (www. biologiezentrum.at).

Fixed phagotrophic flagellates were measured by the use of a semi-automatic image analysis system (Lucia D V3.52 laboratory imaging software; for details see Sonntag et al. 2000). Ciliate dimensions were either measured on living specimens, if available, or on QPS-stained individuals with an eyepiece micrometer. Cell volumes of all protists were calculated from appropriate geometric shapes. Neither correction factors for biovolumes, nor conversion factors for biomasses were applied, as shrinkage/enlargement of ciliate cells is species specific and errors might increase (for details see Pfister et al. 1999). However, for the more-or-less uniform phagotrophic flagellates (see below), we applied the carbon conversion factor of Menden-Deuer \& Lessard (2000).

For the size fractionation of chl $a, 21$ of lake water was filtered in cascades over nylon $(33 \mu \mathrm{m}, 11 \mu \mathrm{m})$ and GF/F filters (Teubner \& Dokulil 2002) and analysed according to APHA (1992) and Wright et al. (1991).

The persistence in the ciliate assemblage was measured as Bray-Curtis similarity between each pair of successive monthly samples. The similarity was based on continuous data, i.e. we considered species that represented $>1 \%$ of the total abundance over seasons and depths ( $\mathrm{n}=192)$, respectively. Further, we calculated the net change $\left(k_{a}\right)$ of ciliate abundance $(a)$ with time $(t)$ as:

$$
k_{a}=\frac{\ln a_{2}-\ln a_{1}}{t_{2}-t_{1}}
$$

Therefore, we used the same time intervals as for BrayCurtis similarity. As most of the abundant ciliates (35 species) were not distributed normally (Kolmogorov-Smirnov), changes in the ciliate assemblage were analysed by non-metric multidimensional scaling (NMS, based on the standardised Bray-Curtis distance matrix), with 2 predefined dimensions to reduce the final stress of the ordination to 0.12 (Clarke 1993). Stress values explain the correspondence between the matrix and the final plot, i.e. ' 0 ' in the case of perfect concordance; $<0.05$ (5\%), very good concordance; and between 0.05 and 0.30 , reliable concordance. Changes were separated for time and depth along the first and the second NMS axis, respectively, and their relationship was analysed by Spearman rank correlations. Bray-Curtis similarity and NMS were carried out with the software packages PRIMER 5 and PCORD 4 for Windows, respectively.

Following the literature (Foissner et al. 1999), we catagorised the detected ciliates into 4 functional guilds, i.e. algivorous, bacterivorous, mixotrophic and omnivorous. The potential food resources were heterotrophic bacteria, 3 size fractions of chl a $(<11 \mu \mathrm{m}$, 11-33 $\mu \mathrm{m}$ and $>33 \mu \mathrm{m}$ ) and phagotrophic flagellates. The relationship between the protists and their potential food sources was analysed by stepwise multiple linear regressions (MLR) and Pearson's correlation after log-transformation (data transformed to normal distribution). The persistence of the ciliate assemblage over seasons and depths was analysed by notched boxwhisker plots created in SYSTAT 8.0 for Windows. Boxes were notched at the median, with $95 \%$ confidence intervals. The length of each box corresponds to $50 \%$ of the values used for the analysis. Statistically significant differences between data sets are indicated by non-overlapping notches (equal to $95 \%$ confidence limit).

\section{RESULTS AND DISCUSSION}

\section{Ciliates}

The distribution patterns for ciliates over seasons and depths at the 3 sampling sites VI, EB and RB in Traunsee are shown in Figs. 1A \& 2. Highest cell densities occurred in the top $30 \mathrm{~m}$ at all sites, including the euphotic zone, and in epi- and metalimnetic strata during summer stratification (Fig. 1A, Tables 1 \& 2). Abundance and biovolume of ciliates were not significantly different between the 3 sampling sites from 0 to $40 \mathrm{~m}$ depths (Fig. 2E). We observed 3 peaks in abundance and biovolume, i.e. in March (with highest values at VI), in May at the time of the phytoplankton maximum and a major peak in autumn (Fig. 1A, 

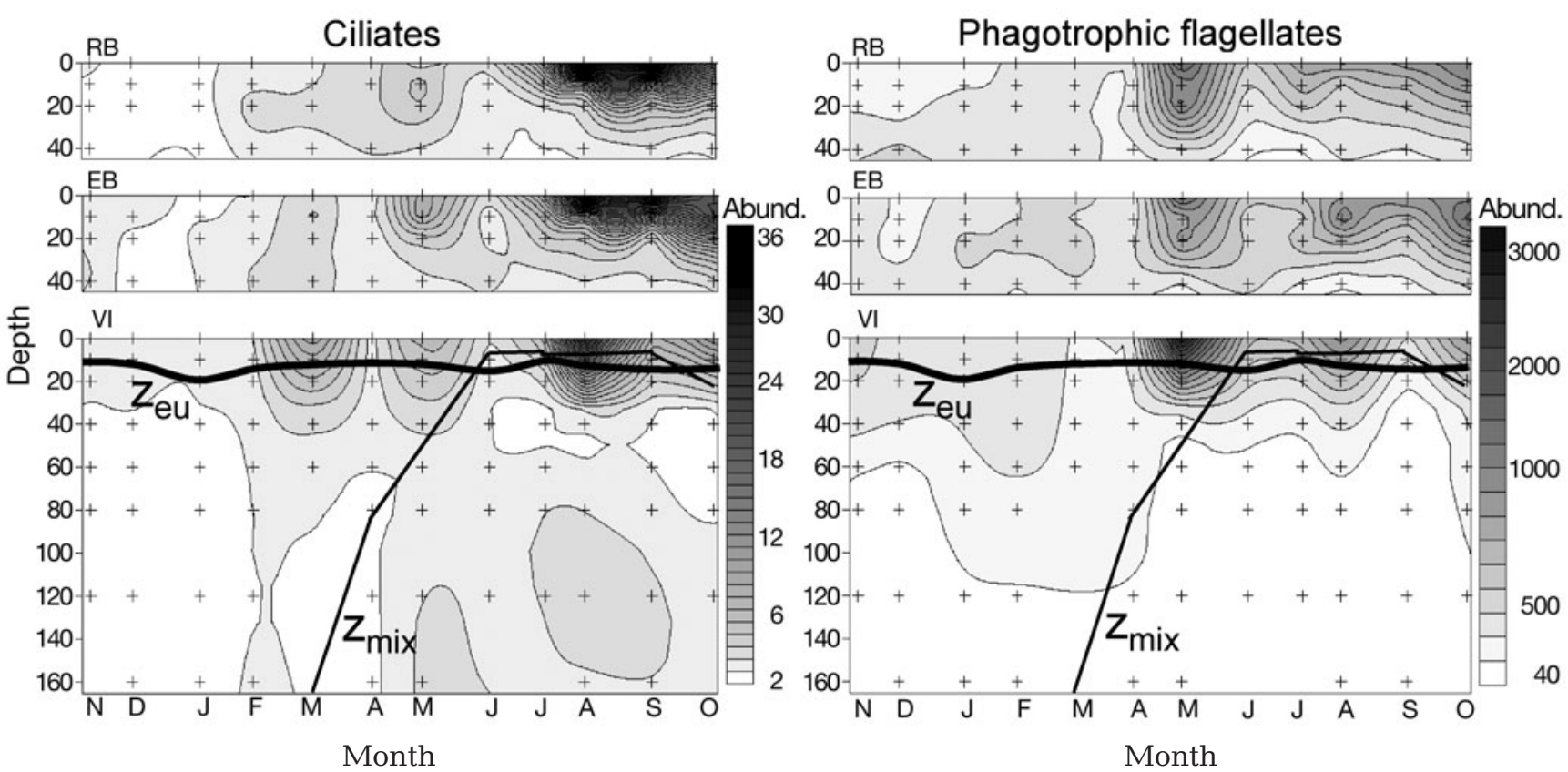

Fig. 1. Vertical and seasonal distribution of the abundance of ciliates (left panel, cells $\mathrm{ml}^{-1}$ ) and phagotrophic flagellates (right panel, cells $\mathrm{ml}^{-1}$ ) at the 3 sites (EB: Ebensee Bay; RB: Rindbach Bay; VI: Viechtau) in Traunsee from November 1997 through October 1998 (crosses: sampling dates and depths; lines: mixing depth $\left[z_{\text {mix }}\right]$ and euphotic zone $\left[z_{\text {eu }}\right]$ )

Table 2, see also Sonntag et al. 2002). Long-term studies on mesotrophic lakes in temperate zones generally showed a bimodal seasonal pattern, with distinct peaks in spring (major peak) and in summer/autumn (Müller et al. 1991a,b, review of Laybourn-Parry 1994, Schweizer 1994, Pfister et al. 2002). Throughout the year, Rimostrombidium brachykinetum/Rimostrombidium hyalinum (not recorded separately), Rimostrombidium humile and Balanion planctonicum were the most abundant ciliate species in the surface waters, i.e. they accounted for $44 \%$ of the annual mean abundance and $15 \%$ of the annual mean biovolume, respectively (Table 2). Further quantitatively important ciliates were Urotricha spp. $<50 \mu \mathrm{m}$, Pelagohalteria cirrifera/Halteria bifurcata, Limnostrombidium pelagicum, Pelagostrombidium fallax/Pelagostrombidium mirabile (not recorded separately due to taxonomical ambiguities - see discussion in Foissner et al. 1999), Tintinnopsis cylindrata, Tintinnidium pusillum and Histiobalantium bodamicum.

The relative contribution of the different ciliate groups to total ciliate abundance from November 1997 through October 1998 is shown in Fig. 3. The dominant group in the top $40 \mathrm{~m}$ was the Oligotrichida, followed by Prostomatida > Hymenostomata > Gymnostomatea/ Peritrichia, while in the 60 to 160 m layers Hymenostomata dominated over Oligotrichida > Gymnostomatea $>$ Prostomatida $>$ Peritrichia. Predominance of oligotrichs ('Oligotrichetea' as defined by Foissner et al. 1991) has been reported earlier for oligotrophic lakes by Beaver \& Crisman (1989) in Florida, James et al. (1995) for Lake Taupo in New Zealand and Félip et al. (1999) for the $70 \mathrm{~m}$ deep, alpine Lake Redó in the Pyrenees, Spain. As already shown elsewhere, the trophic status of a lake affects the composition of pelagic ciliate assemblages (e.g. Beaver \& Crisman 1989, Pfister et al. 2002). In an investigation of several meso- to hypertrophic shallow lakes (<10 m depth) in northern Germany, Pfister et al. (2002) found that eutrophic lakes generally showed the most diverse ciliate assemblage in all seasons sampled, while mesotrophic lakes were dominated by oligotrichs and peritrichs in spring/summer and prostomatids and hymenostomatids in autumn. The dominant groups in hypertrophic lakes were oligotrichs, peritrichs, hypotrichs, heterotrichs and prostomatids. Under eutrophic and hypertrophic conditions high bacterial numbers support large assemblages of scuticociliates, mostly of the genera Cyclidium and Uronema, and oligotrichs, e.g. Halteria spp. (Nakano et al. 1998, Šimek et al. 2000).

In Traunsee, we identified around 60 pelagic ciliate species, and recent findings of Sonntag \& Foissner (2004, unpubl. data) indicate the occurrence of several further still poorly or undescribed taxa. With depth, we followed the increase of various scuticociliates (1 probably undescribed species, Histiobalantium bodamicum, and others) and confirm the assumption of Müller et al. (1991b) that a decrease of ciliates with depth and low numbers of scuticociliates are characteristic for deep lakes with aerobic hypolimnia. In 2 neighbouring lakes, 

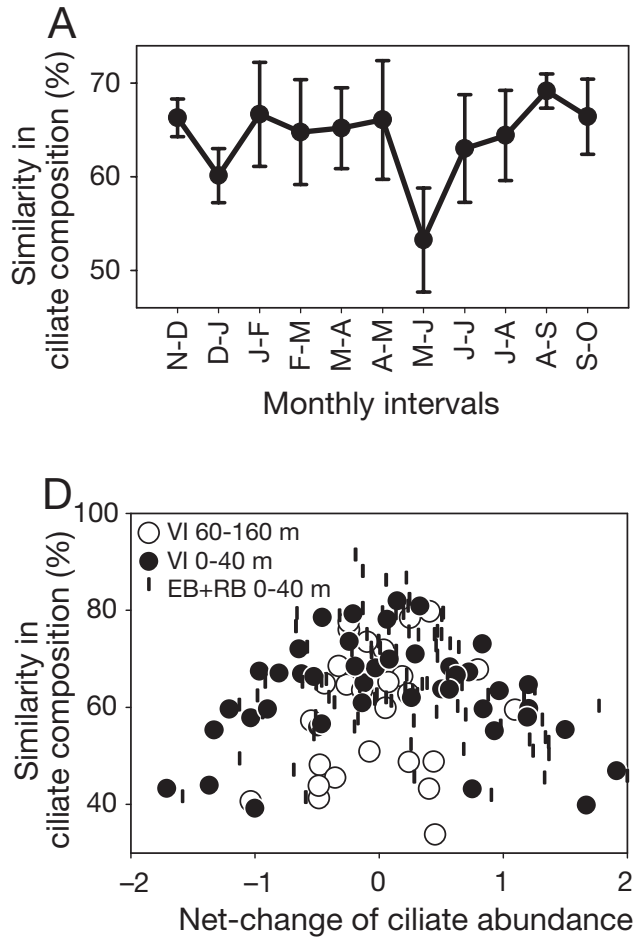

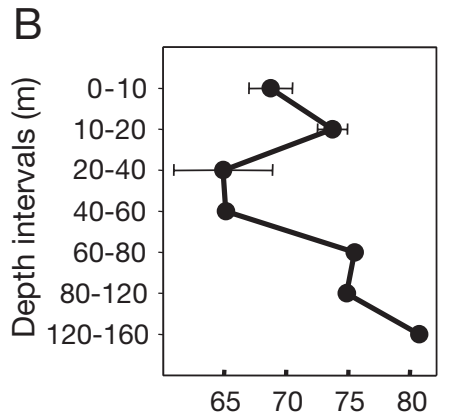

Similarity in ciliate composition (\%)

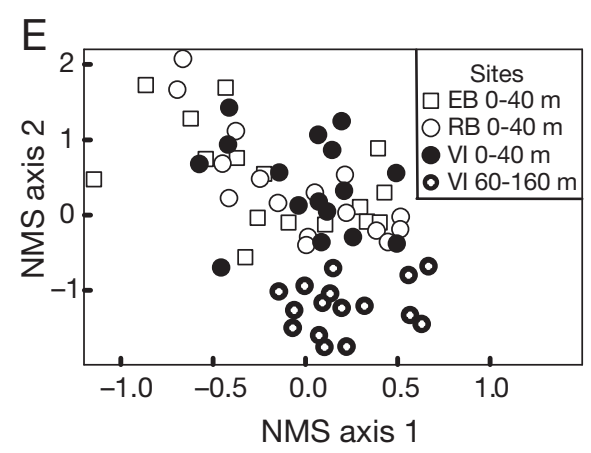

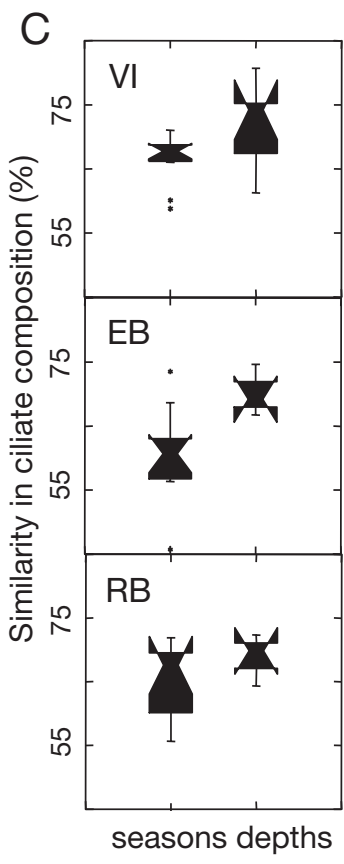

Fig. 2. Similarity in the ciliate assemblage between depths and seasons. (A) Similarity according to the Bray-Curtis index between successive monthly samples for the 3 sites (mean \pm SD). (B) Same as Panel A for depths. (C) Similarity with seasons and along depths for each site as notched box-whisker plots. (D) Relationship between the monthly change in the ciliate species composition (Bray-Curtis similarity) and the monthly net change of the ciliate abundance for individual sites and depths. Sites EB and RB not labelled separately as their distributions are similar. (E) Non-metric multidimensional scaling analysis (NMS) of the 35 most abundant ciliate taxa. Each point represents the mean by season and depth for each sampling site: points were labelled by sites. The label overlay for seasons and depths for the first and the second axis, respectively, is shown in Fig. 4A,F. Stress: 0.12 (12\%)

i.e. the oligotrophic Attersee and the oligo-mesotrophic Hallstättersee, we observed the same tendency (Sonntag et al. 2002). In Traunsee, the ciliate assemblage changed significantly with depth in relation to environmental parameters (Fig. 2B, Table 3). Furthermore, no anaerobic ciliates were found during the investigation period, which agrees with our observations that the whole water column was always oxygenated (Klammer et al. 2002). Occasionally, the main tributary, the Traun River, carried some single cyrtophorid ciliates into the lake. As the river water flows along the south-west coast of Traunsee, we detected such ciliates mainly at RB, but also at VI and EB.

Throughout the year, changes in algal and bacterial numbers led to specific ciliate successions (Figs. 4 \& 5). Ciliate functional guilds were related to their potential food resources (Figs. 4 \& 5, Tables $2 \& 4$ ). Throughout the year, total ciliate numbers were composed of around $90 \%$ algivores, $8 \%$ mixotrophs and $2 \%$ bacteri- and omnivores (Fig. 5C). The most predictive food sources for total, algivorous and bacterivorous ciliates were heterotrophic bacteria, on the one hand, and phytoplankton species in the size fraction of $11-33 \mu \mathrm{m}$, on the other hand (Table 4). This medium-sized phytoplankton fraction was composed of $36 \%$ diatoms, $26 \%$ cryptophytes, 22\% chrysophytes, 9\% chlorophytes and $7 \%$ dinoflagellates. Bacterivorous species occurred primarily in the deeper layers, from 60 to $160 \mathrm{~m}$, where they accounted for around $50 \%$ of total abundance. A similar increase in abundance with depth was observed earlier by Taylor \& Heynen (1987), Müller et al. (1991a) and Carrias et al. (1998a). The decrease in potential food sources, i.e. bacteria, phagotrophic flagellates and algae, from surface to deeper layers was significantly related to changes in the ciliate assemblage (Fig. 4F-J). Furthermore, the ciliate assemblage structure along depths was also significantly associated with depth gradients of temperature, conductivity and concentrations of dissolved organic carbon (DOC), total phosphorus, oxygen and chloride (NMS Axis 2; Table 3A). Food sources, however, were the primary factors driving the ciliate assemblage structure along the depth gradient (correlation coefficients $>0.81$, p < 0.01; Fig. 4I-J) compared to environmental parameters ( NMS Axis 2: correlation coefficients $<0.68, \mathrm{p}<0.01$; Table 3A). 
Table 2. Annual mean abundance of total and single ciliate species (cells $\left.\mathrm{l}^{-1}\right)$, ciliate biovolume $\left(\mathrm{mm}^{3} \mathrm{l}^{-1}\right)$, free-living flagellates $\left(10^{6}\right.$ cells $\left.\mathrm{l}^{-1}\right)$, epiphytic flagellates $\left(10^{3} \mathrm{cells}^{-1}\right)$, heterotrophic bacteria $\left(10^{9} \mathrm{cells}^{-1}\right)$, picocyanobacteria $\left(10^{7}\right.$ cells $\left.\mathrm{l}^{-1}\right)$ and chl a $\left(\mu \mathrm{g} \mathrm{l}^{-1}\right.$ ) in Traunsee from Nov 1997 through Oct 1998. Minimum and maximum values are given in brackets. Ciliates present below 0.2 cells $\mathrm{ml}^{-1}$ are recorded as 'single' findings. Black boxes indicate months with highest values (peaks), grey boxes the presence and white boxes the absence of the respective parameter. Values $0-40 \mathrm{~m}$ were depth and site integrated, values for 60-160 m integrated for VI only. Ciliates' preferred food or feeding mode are given as: a: algae, b: bacteria, m: mixotrophic, o: omnivorous, ?: food not known

\begin{tabular}{|c|c|c|c|c|c|c|c|c|c|c|c|c|c|c|c|}
\hline & $\begin{array}{l}\text { Depths } \\
\text { (m) }\end{array}$ & $\mathrm{N}$ & $\mathrm{D}$ & $\mathrm{J}$ & $\mathrm{F}$ & 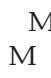 & $\begin{array}{c}\text { Montl } \\
\text { A }\end{array}$ & th & $\mathrm{J}$ & $\mathrm{J}$ & A & $\mathrm{S}$ & $\mathrm{O}$ & $\begin{array}{l}\text { Abundance } \\
\text { or volume }\end{array}$ & $\begin{array}{l}\text { Preferred food } \\
\text { or feeding mode }\end{array}$ \\
\hline $\begin{array}{l}\text { Ciliate abundance } \\
\quad\left(\text { cells } 1^{-1}\right)\end{array}$ & $\begin{array}{c}0-40 \\
60-160\end{array}$ & 口 & 口 & 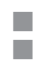 & 口 & 口 & 무 & $\mathbf{\square}$ & 口 & 口 & $\mathbf{\square}$ & $\mathbf{\square}$ & 口 & $\begin{array}{l}4435(235-36574) \\
1387(320-2764)\end{array}$ & \\
\hline $\begin{array}{l}\text { Ciliate biovolume } \\
\left(\mathrm{mm}^{3} \mathrm{l}^{-1}\right)\end{array}$ & $\begin{array}{c}0-40 \\
60-160\end{array}$ & 口 & 口 & 口 & $\square$ & 口 & 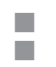 & $\mathbf{\square}$ & 口 & 口 & $\mathbf{\square}$ & 口 & 뭄 & $\begin{array}{l}0.069(0.015-0.973) \\
0.009(0.002-0.024)\end{array}$ & \\
\hline $\begin{array}{l}\text { Free-living flagellate } \\
\quad \text { abundance }\left(10^{6} \text { cells } 1^{-1}\right)\end{array}$ & $\begin{array}{c}0-40 \\
60-160\end{array}$ & 口 & 口 & 무 & 口 & $\square$ & 口 & $\mathbf{\square}$ & 口 & ㅁ. & 口 & 口 & 口 & $\begin{array}{c}0.6(0.05-2.8) \\
0.16(0.04-0.34)\end{array}$ & \\
\hline $\begin{array}{l}\text { Free-living flagellate } \\
\text { biovolume }\left(\mathrm{mm}^{3} \mathrm{l}^{-1}\right)\end{array}$ & $\begin{array}{c}0-40 \\
60-160\end{array}$ & 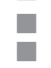 & 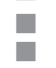 & 口 & $\square$ & 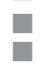 & 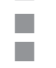 & $\square$ & 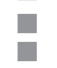 & 口 & 口 & 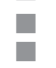 & 口 & $\begin{array}{l}0.014(0.005-0.085) \\
0.006(0.001-0.014)\end{array}$ & \\
\hline $\begin{array}{l}\text { Sessile flagellate } \\
\quad \text { abundance }\left(10^{3} \text { cells } 1^{-1}\right)\end{array}$ & $\begin{array}{c}0-40 \\
60-160\end{array}$ & $\begin{array}{l}\square \\
\square\end{array}$ & $\begin{array}{l}\square \\
\square\end{array}$ & $\begin{array}{l}\square \\
\square\end{array}$ & $\begin{array}{l}\square \\
\square\end{array}$ & $\begin{array}{l}\square \\
\square\end{array}$ & $\begin{array}{l}\square \\
\square\end{array}$ & $\square$ & 口 & ㅁ & $\mathbf{a}$ & $\square$ & 口 & $\begin{array}{l}5.8(0-134.0) \\
2.0(0-25.0)\end{array}$ & \\
\hline $\begin{array}{l}\text { Bacterial abundance } \\
\left(10^{9} \text { cells } 1^{-1}\right)^{\mathrm{a}}\end{array}$ & $\begin{array}{c}0-40 \\
60-160\end{array}$ & 口 & $\mathbf{\square}$ & 口 & 口 & 口 & 口 & $\mathbf{\square}$ & 口 & $\mathbf{\square}$ & $\mathbf{a}$ & $\mathbf{\square}$ & 口 & $\begin{array}{l}1.4(0.7-2.7) \\
0.6(0.4-1.1)\end{array}$ & \\
\hline $\begin{array}{l}\text { Picocyanobacterial } \\
\text { abundance }\left(10^{7} \text { cells } 1^{-1}\right)^{\mathrm{a}}\end{array}$ & $0-40$ & $\square$ & $\mathbf{\square}$ & $\mathbf{\square}$ & $\mathbf{\square}$ & घ & $\mathbf{\square}$ & $\mathbf{\square}$ & $\mathbf{\square}$ & $\mathbf{\square}$ & $\mathbf{a}$ & 口 & $\mathbf{\square}$ & $1.9(0.2-9.9)$ & \\
\hline Chl $a\left(\mu g l^{-1}\right)$ & $0-20$ & घ & $\mathbf{\square}$ & $\mathbf{\square}$ & $\square$ & $\square$ & $\mathbf{\square}$ & $\mathbf{\square}$ & $\mathbf{\square}$ & $\mathbf{\square}$ & $\mathbf{\square}$ & $\mathbf{\square}$ & 口 & $1.1(0.1-3.4)$ & \\
\hline \multicolumn{16}{|l|}{ Oligotrichida (cells l $^{-1}$ ) } \\
\hline $\begin{array}{l}\text { Codonella cratera } \\
\text { (Leidy, 1877) }\end{array}$ & $0-40$ & $\square$ & $\square$ & $\square$ & $\square$ & $\square$ & $\mathbf{\square}$ & $\mathbf{\square}$ & $\square$ & $\square$ & $\square$ & $\square$ & $\square$ & Single & $\mathrm{a}$ \\
\hline $\begin{array}{l}\text { Limnostrombidium } \\
\text { pelagicum (Kahl, 1932) }\end{array}$ & $\begin{array}{c}0-40 \\
60-160\end{array}$ & $\square$ & $\square$ & $\begin{array}{l}\square \\
\square\end{array}$ & $\begin{array}{l}\square \\
\square\end{array}$ & $\begin{array}{l}\square \\
\square\end{array}$ & $\begin{array}{l}\square \\
\square\end{array}$ & 口 & 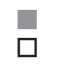 & $\square$ & $\mathbf{a}$ & $\mathbf{\square}$ & 문 & $\begin{array}{l}121(0-3833) \\
\text { Single }\end{array}$ & $\mathrm{a}$ \\
\hline $\begin{array}{l}\text { Pelagohalteria cirrifera } \\
\text { (Kahl, 1932)/ } \\
\text { Halteria bifurcata } \\
\text { (Tamar, 1968) }\end{array}$ & $\begin{array}{c}0-40 \\
60-160\end{array}$ & $\square$ & $\mathbf{a}$ & 口 & $\mathbf{\square}$ & 口 & 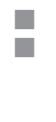 & 口 & 要 & 口 & $\mathbf{a}$ & $\mathbf{\square}$ & 口 & $\begin{array}{l}367(0-2223) \\
142(0-620)\end{array}$ & $\mathrm{a}$ \\
\hline $\begin{array}{l}\text { Pelagohalteria viridis } \\
\text { (Fromentel, 1876) }\end{array}$ & $0-40$ & घ & $\mathbf{\square}$ & $\square$ & $\square$ & घ & $\square$ & $\square$ & $\mathbf{\square}$ & $\mathbf{\square}$ & $\mathbf{\square}$ & $\mathbf{\square}$ & 口 & $151(0-3153)$ & $\mathrm{m}$ \\
\hline $\begin{array}{l}\text { Pelagostrombidium fallax } \\
\quad \text { (Zacharias, 1895)/ } \\
\text { P. mirabile (Penard, 1916) }\end{array}$ & $\begin{array}{c}0-40 \\
60-160\end{array}$ & $\square$ & 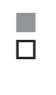 & $\square$ & 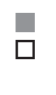 & 口 & 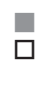 & 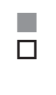 & 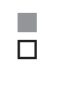 & $\square$ & 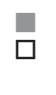 & 旦 & $\square$ & $\begin{array}{l}83 \text { (0-3426) } \\
\text { Single }\end{array}$ & $\mathrm{m}$ \\
\hline $\begin{array}{l}\text { Rimostrombidium } \\
\text { brachykinetum } \\
\text { (Krainer, 1995)/R. hyalinum } \\
\text { (Mirabdullaev, 1985) }\end{array}$ & $\begin{array}{c}0-40 \\
60-160\end{array}$ & 口 & 要 & 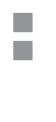 & 口 & 口 & 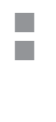 & 表 & 豆 & 뭄 & $\mathbf{a}$ & 口 & 뭄 & $\begin{array}{l}884(47-10548) \\
128(16-360)\end{array}$ & $\mathrm{a}$ \\
\hline $\begin{array}{l}\text { Rimostrombidium } \\
\text { humile (Penard, 1922) }\end{array}$ & $\begin{array}{c}0-40 \\
60-160\end{array}$ & 口 & $\mathbf{a}$ & ㅁ & 口 & $\mathbf{\square}$ & 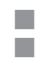 & 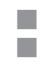 & 口 & ㅁ & $\square$ & 口 & 口 & $\begin{array}{r}287(0-4151) \\
27(0-161)\end{array}$ & $\mathrm{a}$ \\
\hline $\begin{array}{l}\text { Rimostrombidium } \\
\text { lacustris (Foissner, } \\
\text { Skogstad \& Pratt, 1988) }\end{array}$ & $\begin{array}{c}0-40 \\
60-160\end{array}$ & $\square$ & $\begin{array}{l}\square \\
\square\end{array}$ & $\begin{array}{l}\square \\
\square\end{array}$ & 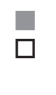 & $\mathbf{\square}$ & $\begin{array}{l}\square \\
\square\end{array}$ & 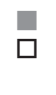 & $\begin{array}{l}\square \\
\square\end{array}$ & $\begin{array}{l}\square \\
\square\end{array}$ & 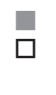 & $\begin{array}{l}\square \\
\square\end{array}$ & $\square$ & $\begin{array}{l}30 \text { (0-905) } \\
\text { Single }\end{array}$ & $\mathrm{a}$ \\
\hline $\begin{array}{l}\text { Tintinnopsis cylindrata } \\
\text { Kofoid \& Campbell, } 1929\end{array}$ & $\begin{array}{c}0-40 \\
60-160\end{array}$ & $\begin{array}{l}\square \\
\square\end{array}$ & $\begin{array}{l}\square \\
\square\end{array}$ & $\begin{array}{l}\square \\
\square\end{array}$ & $\begin{array}{l}\square \\
\square\end{array}$ & $\begin{array}{l}\square \\
\square\end{array}$ & $\begin{array}{l}\square \\
\square\end{array}$ & 口 & 口 & 口 & 口 & 口 & 口 & $\begin{array}{c}246(0-12153) \\
4(0-61)\end{array}$ & $\mathrm{a}$ \\
\hline $\begin{array}{l}\text { Tintinnidium pusillum } \\
\text { Entz, } 1909\end{array}$ & $\begin{array}{c}0-40 \\
60-160\end{array}$ & $\begin{array}{l}\square \\
\square\end{array}$ & 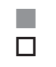 & $\begin{array}{l}\square \\
\square\end{array}$ & 口 & 口 & 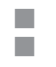 & $\mathbf{\square}$ & $\mathbf{q}$ & $\square$ & 口 & 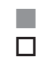 & 口 & $\begin{array}{c}88(0-4248) \\
8(0-76)\end{array}$ & $\mathrm{a}$ \\
\hline \multicolumn{16}{|l|}{ Prostomatida (cells $\mathbf{l}^{-1}$ ) } \\
\hline $\begin{array}{l}\text { Balanion planctonicum } \\
\text { (Foissner, Oleksiv \& } \\
\text { Müller, 1990) }\end{array}$ & $\begin{array}{c}0-40 \\
60-160\end{array}$ & 口 & 口 & 口 & 口 & 口 & 口 & 要 & 要 & 뭄 & 口 & 口 & 口 & $\begin{array}{c}611(0-5446) \\
44(0-158)\end{array}$ & $\mathrm{a}$ \\
\hline Coleps spetai Foissner, 1984 & $0-40$ & $\square$ & $\square$ & $\mathbf{\square}$ & $\square$ & 口 & $\square$ & $\square$ & $\square$ & $\square$ & $\mathbf{\square}$ & 口 & $\mathbf{\square}$ & $42(0-1318)$ & $\mathrm{m}$ \\
\hline $\begin{array}{l}\text { Urotricha spp. } \\
\text { (at least } 4 \text { species) }\end{array}$ & $\begin{array}{c}0-40 \\
60-160\end{array}$ & 口 & $\square$ & 무 & 口 & 口 & 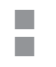 & 口 & 口 & 口 & 口 & 口 & 口 & $\begin{array}{l}526(0-6019) \\
37(0-185)\end{array}$ & $\mathrm{a}$ \\
\hline $\begin{array}{l}\text { Urotricha venatrix } \\
\text { Kahl, } 1935\end{array}$ & $0-40$ & $\square$ & $\square$ & $\square$ & $\square$ & $\square$ & $\square$ & $\square$ & $\square$ & $\square$ & $\mathbf{a}$ & $\mathbf{\square}$ & घ & $9(0-516)$ & o \\
\hline \multicolumn{16}{|l|}{ Gymnostomatea (cells $\mathbf{l}^{-1}$ ) } \\
\hline $\begin{array}{l}\text { Askenasia chlorelligera } \\
\text { Krainer \& Foissner, } 1990\end{array}$ & $\begin{array}{c}0-40 \\
60-160\end{array}$ & $\square$ & 口 & $\begin{array}{l}\square \\
\square\end{array}$ & $\begin{array}{l}\square \\
\square\end{array}$ & $\square$ & 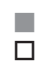 & $\begin{array}{l}\square \\
\square\end{array}$ & 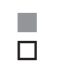 & $\square$ & $\square$ & 口 & 문 & 72 (0-1813) & $\mathrm{m}$ \\
\hline Askenasia sp. ${ }^{\mathrm{b}}$ & $0-40$ & $\square$ & $\square$ & $\square$ & $\square$ & $\square$ & $\square$ & $\square$ & $\square$ & 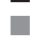 & $\square$ & $\mathbf{\square}$ & 口 & $114(0-3888)$ & a \\
\hline $\begin{array}{l}\text { Askenasia volvox } \\
\text { (Eichwald, 1852)/ } \\
\text { A. acrostomia } \\
\text { Krainer \& Foissner, } 1990\end{array}$ & $\begin{array}{c}0-40 \\
60-160\end{array}$ & $\square$ & $\begin{array}{l}\square \\
\square\end{array}$ & 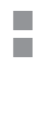 & 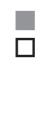 & 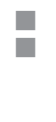 & 口 & 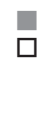 & 要 & $\square$ & $\square$ & 口 & 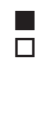 & $\begin{array}{l}37(0-344) \\
3(0-23)\end{array}$ & a \\
\hline
\end{tabular}


Table 2 (continued)

\begin{tabular}{|c|c|c|c|c|c|c|c|c|c|c|c|c|c|c|c|}
\hline & $\begin{array}{l}\text { Depths } \\
\text { (m) }\end{array}$ & $\mathrm{N}$ & $\mathrm{D}$ & $\mathrm{J}$ & $\mathrm{F}$ & $\mathrm{M}^{\mathrm{M}}$ & Tont & $\mathrm{h}$ & $\mathrm{J}$ & $\mathrm{J}$ & $\mathrm{A}$ & $\mathrm{S}$ & $\mathrm{O}$ & $\begin{array}{l}\text { Abundance } \\
\text { or volume }\end{array}$ & $\begin{array}{l}\text { Preferred food } \\
\text { or feeding mode }\end{array}$ \\
\hline $\begin{array}{l}\text { Monodinium chlorelligerum } \\
\text { Krainer, } 1995\end{array}$ & $0-40$ & $\square$ & $\square$ & $\square$ & $\square$ & $\square$ & $\square$ & $\square$ & $\square$ & $\mathbf{\square}$ & $\mathbf{\square}$ & $\mathbf{\square}$ & 口 & $41(0-4217)$ & $\mathrm{m}$ \\
\hline Mesodinium sp. & $\begin{array}{c}0-40 \\
60-160\end{array}$ & 口 & $\begin{array}{l}\square \\
\square\end{array}$ & 口 & 口 & 口 & $\square$ & 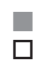 & 口 & 口 & 口 & 口 & 口 & $\begin{array}{l}21(0-172) \\
41(0-184)\end{array}$ & o \\
\hline $\begin{array}{l}\text { Paradileptus } \\
\text { elephantinus (Svec, 1897) }\end{array}$ & $0-40$ & $\square$ & $\square$ & $\square$ & $\square$ & $\square$ & $\square$ & $\square$ & $\square$ & $\square$ & $\square$ & $\mathbf{\square}$ & $\mathbf{\square}$ & $2(0-115)$ & o \\
\hline $\begin{array}{l}\text { Rhabdoaskenasia minima } \\
\text { Krainer \& Foissner } 1990\end{array}$ & $\begin{array}{c}0-40 \\
60-160\end{array}$ & 口 & 口 & $\mathbf{a}$ & 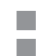 & 口 & 口 & 口 & 口 & 口 & 口 & 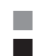 & 口 & $\begin{array}{l}43(0-351) \\
114(0-344)\end{array}$ & $\mathrm{a}$ \\
\hline $\begin{array}{l}\text { Spathidium cf. depressum } \\
\text { Kahl, } 1930\end{array}$ & $\begin{array}{c}0-40 \\
60-160\end{array}$ & $\begin{array}{l}\square \\
\square\end{array}$ & $\begin{array}{l}\square \\
\square\end{array}$ & $\begin{array}{l}\square \\
\square\end{array}$ & $\begin{array}{l}\square \\
\square\end{array}$ & $\begin{array}{l}\square \\
\square\end{array}$ & $\begin{array}{l}\square \\
\square\end{array}$ & $\begin{array}{l}\square \\
\square\end{array}$ & $\begin{array}{l}\square \\
\square\end{array}$ & $\begin{array}{l}\square \\
\square\end{array}$ & $\begin{array}{l}\square \\
\square\end{array}$ & 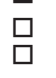 & 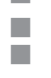 & $\begin{array}{l}\text { Single } \\
\text { Single }\end{array}$ & $\mathrm{a}$ \\
\hline \multicolumn{16}{|l|}{ Pleurostomatida (cells $\mathbf{l}^{-1}$ ) } \\
\hline $\begin{array}{l}\text { Enchelys gasterosteus } \\
\text { Kahl, } 1926\end{array}$ & $0-40$ & $\square$ & $\square$ & $\square$ & $\square$ & $\square$ & घ & $\square$ & $\square$ & 口 & $\square$ & $\square$ & $\square$ & Single & o \\
\hline Lacrymaria sp. ${ }^{\mathrm{b}}$ & $\begin{array}{c}0-40 \\
60-160\end{array}$ & $\begin{array}{l}\square \\
\square\end{array}$ & $\begin{array}{l}\square \\
\square\end{array}$ & $\begin{array}{l}\square \\
\square\end{array}$ & $\begin{array}{l}\square \\
\square\end{array}$ & $\begin{array}{l}\square \\
\square\end{array}$ & $\square$ & $\square$ & 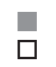 & $\begin{array}{l}\square \\
\square\end{array}$ & $\begin{array}{l}\square \\
\square\end{array}$ & $\begin{array}{l}\square \\
\square\end{array}$ & $\begin{array}{l}\square \\
\square\end{array}$ & $\begin{array}{l}\text { Single } \\
\text { Single }\end{array}$ & o \\
\hline $\begin{array}{l}\text { Lagynophrya acuminata } \\
\text { Kahl, 1935/ } \\
\text { Lagynophrya sp. }{ }^{\mathrm{b}}\end{array}$ & $\begin{array}{c}0-40 \\
60-160\end{array}$ & $\begin{array}{l}\square \\
\square\end{array}$ & $\begin{array}{l}\square \\
\square\end{array}$ & $\begin{array}{l}\square \\
\square\end{array}$ & $\begin{array}{l}\square \\
\square\end{array}$ & 뭄 & $\square$ & $\begin{array}{l}\square \\
\square\end{array}$ & $\begin{array}{l}\square \\
\square\end{array}$ & 口 & 口 & $\square$ & $\square$ & $\begin{array}{l}8 \text { (0-213) } \\
\text { Single }\end{array}$ & $\mathrm{a}$ \\
\hline $\begin{array}{l}\text { Amphileptus piger } \\
\text { (Vuxanovici, 1962) }\end{array}$ & $\begin{array}{c}0-40 \\
60-160\end{array}$ & $\begin{array}{l}\square \\
\square\end{array}$ & $\begin{array}{l}\square \\
\square\end{array}$ & $\begin{array}{l}\square \\
\square\end{array}$ & $\begin{array}{l}\square \\
\square\end{array}$ & $\begin{array}{l}\square \\
\square\end{array}$ & $\begin{array}{l}\square \\
\square\end{array}$ & 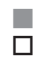 & 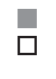 & $\square$ & 口 & $\square$ & $\begin{array}{l}\square \\
\square\end{array}$ & $\begin{array}{l}\text { Single } \\
\text { Single }\end{array}$ & $?$ \\
\hline \multicolumn{16}{|l|}{ Hypotrichia (cells $\mathbf{l}^{-1}$ ) } \\
\hline $\begin{array}{l}\text { Aspidisca cicada } \\
\text { (Mueller, 1786) }\end{array}$ & $0-40$ & $\square$ & $\square$ & $\square$ & $\square$ & - & $\square$ & घ & $\square$ & $\square$ & $\square$ & $\square$ & $\square$ & Single & a \\
\hline $\begin{array}{l}\text { Holosticha spp. }{ }^{\mathrm{c}} \\
\text { (at least } 2 \text { species) }\end{array}$ & $0-40$ & $\square$ & $\square$ & $\square$ & $\square$ & $\mathbf{\square}$ & $\square$ & $\square$ & $\square$ & $\square$ & $\square$ & $\square$ & $\square$ & Single & o \\
\hline Uroleptus sp. ${ }^{\mathrm{d}}$ & $0-40$ & $\square$ & $\square$ & $\square$ & $\square$ & घ & $\square$ & $\square$ & $\mathbf{\square}$ & $\square$ & $\square$ & $\mathbf{\square}$ & $\square$ & Single & $\mathrm{m}$ \\
\hline \multicolumn{16}{|l|}{ Hymenostomata (cells $\mathrm{l}^{-1}$ ) } \\
\hline $\begin{array}{l}\text { Cinetochilum margaritaceum } \\
\text { (Ehrenberg, 1831) }\end{array}$ & $0-40$ & $\square$ & $\square$ & $\mathbf{\square}$ & $\mathbf{\square}$ & $\square$ & $\square$ & 口 & $\square$ & $\square$ & $\square$ & $\square$ & $\square$ & Single & $\mathrm{b}$ \\
\hline $\begin{array}{l}\text { Histiobalantium bodamicum } \\
\text { Krainer \& Müller, } 1995\end{array}$ & $\begin{array}{c}0-40 \\
60-160\end{array}$ & 口 & 口 & 表 & 旦 & 口 & 口 & 口 & ㅁ & $\mathbf{\square}$ & 口 & 口 & ㅁ & $\begin{array}{r}268(0-2035) \\
52(0-246)\end{array}$ & $\mathrm{a}$ \\
\hline Paramecium sp. & $0-40$ & $\square$ & $\mathbf{\square}$ & $\square$ & $\square$ & $\mathbf{\square}$ & $\square$ & $\square$ & $\square$ & $\square$ & $\square$ & $\square$ & $\square$ & Single & $\mathrm{b}$ \\
\hline Pleuronema sp. & $0-40$ & $\square$ & $\square$ & $\square$ & $\square$ & 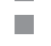 & $\square$ & $\square$ & $\square$ & $\square$ & $\square$ & $\square$ & $\square$ & Single & $\mathrm{b}$ \\
\hline Scuticociliata $^{\mathrm{b}}$ & $\begin{array}{c}0-40 \\
60-160\end{array}$ & 口 & $\square$ & 口 & 口 & 口 & 口 & 口 & 口 & 豆 & 口 & 무 & 무 & $\begin{array}{c}21(0-453) \\
528(64-1624)\end{array}$ & $\mathrm{b}$ \\
\hline $\begin{array}{l}\text { Scuticociliata } \\
\text { (at least } 4 \text { species) }\end{array}$ & $\begin{array}{c}0-40 \\
60-160\end{array}$ & 문 & $\square$ & $\square$ & $\square$ & 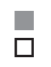 & 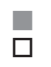 & $\square$ & $\mathbf{0}$ & 口 & 口 & $\square$ & 口 & $\begin{array}{c}\text { Single } \\
186(0-988)\end{array}$ & $\mathrm{b}$ \\
\hline $\begin{array}{l}\text { Uronema nigricans } \\
\text { (Mueller, 1786) }\end{array}$ & $0-40$ & $\square$ & $\square$ & $\square$ & $\square$ & $\square$ & $\square$ & $\square$ & $\square$ & $\mathbf{\square}$ & $\square$ & $\mathbf{\square}$ & $\square$ & Single & $\mathrm{b}$ \\
\hline \multicolumn{16}{|l|}{ Peritrichia (cells $\mathbf{l}^{-1}$ ) } \\
\hline Epistylis sp. & $0-40$ & 口 & $\square$ & $\square$ & $\square$ & $\square$ & $\square$ & $\square$ & $\square$ & $\square$ & $\mathbf{\square}$ & $\square$ & $\square$ & $12(0-1299)$ & $\mathrm{b}$ \\
\hline $\begin{array}{l}\text { Pelagovorticella natans } \\
\text { (Fauré-Fremiet, 1924) }\end{array}$ & $\begin{array}{c}0-40 \\
60-160\end{array}$ & $\square$ & 口 & a & $\square$ & 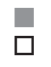 & 口 & 昌 & $\square$ & 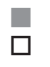 & $\square$ & $\square$ & 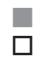 & $\begin{array}{l}18(0-344) \\
\text { Single }\end{array}$ & $\mathrm{b}$ \\
\hline $\begin{array}{l}\text { Pseudohaplocaulus } \\
\text { infravacuolatus Foissner } \\
\text { \& Brozek, } 1996 \text { + Vorticella } \\
\text { chlorellata Stiller, } 1940\end{array}$ & $0-40$ & $\square$ & $\square$ & $\square$ & $\square$ & $\square$ & $\square$ & $\square$ & $\square$ & 口 & $\mathbf{\square}$ & $\mathbf{\square}$ & $\square$ & $13(0-1462)$ & a \& m \\
\hline $\begin{array}{l}\text { Vaginicola ingenita } \\
\text { (Mueller, 1786) }\end{array}$ & $\begin{array}{c}0-40 \\
60-160\end{array}$ & 문 & $\begin{array}{l}\square \\
\square\end{array}$ & $\begin{array}{l}\square \\
\square\end{array}$ & $\begin{array}{l}\square \\
\square\end{array}$ & $\begin{array}{l}\square \\
\square\end{array}$ & $\begin{array}{l}\square \\
\square\end{array}$ & $\begin{array}{l}\square \\
\square\end{array}$ & 口 & $\mathbf{\square}$ & $\square$ & $\square$ & $\square$ & $\begin{array}{l}28(0-344) \\
5(0-66)\end{array}$ & $\mathrm{b}$ \\
\hline $\begin{array}{l}\text { Vorticella vernalis } \\
\text { Stokes, } 1887\end{array}$ & $\begin{array}{c}0-40 \\
60-160\end{array}$ & $\square$ & 口 & $\square$ & 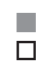 & 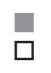 & 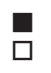 & 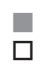 & 表 & 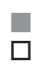 & 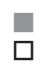 & 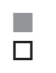 & $\square$ & $\begin{array}{l}62 \text { (0-602) } \\
\text { Single }\end{array}$ & $\mathrm{a}$ \\
\hline \multicolumn{16}{|l|}{ Suctoria (cells $\mathbf{l}^{-1}$ ) } \\
\hline $\begin{array}{l}\text { Gajewskaiophrya melosirae } \\
\text { (Gajewskaja, 1933) }\end{array}$ & $\begin{array}{c}0-40 \\
60-160\end{array}$ & $\square$ & $\begin{array}{l}\square \\
\square\end{array}$ & $\begin{array}{l}\square \\
\square\end{array}$ & $\begin{array}{l}\square \\
\square\end{array}$ & 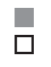 & $\begin{array}{l}\square \\
\square\end{array}$ & 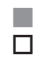 & 要 & 要 & 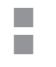 & $\square$ & 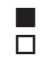 & 8 (0-172) & o \\
\hline \multicolumn{16}{|l|}{ Cyrtophorida (cells l $^{-1}$ ) } \\
\hline $\begin{array}{l}\text { Gastronauta membranaceus } \\
\text { Buetschli, } 1889\end{array}$ & $0-40$ & $\square$ & $\square$ & $\square$ & $\square$ & $\square$ & $\square$ & $\square$ & $\square$ & $\mathbf{\square}$ & $\square$ & $\square$ & $\square$ & Single & $\mathrm{b}$ \\
\hline $\begin{array}{l}\text { Pseudochilodonopsis fluviatilis }{ }^{c} \\
\text { Foissner, } 1988\end{array}$ & $0-40$ & $\square$ & $\square$ & $\square$ & $\square$ & - & $\square$ & $\square$ & $\square$ & $\square$ & $\square$ & $\square$ & $\square$ & Single & a \\
\hline Cyrtophorida $^{\mathrm{c}}$ (at least 2 species) & ) $0-40$ & - & 口 & 口 & $\square$ & $\square$ & $\square$ & $\square$ & $\square$ & 口 & $\square$ & $\square$ & $\square$ & Single & $\mathrm{a}$ \\
\hline $\begin{array}{l}\text { a Data from Klammer et al. (2002 } \\
\text { b Probably new species } \\
{ }^{c} \text { Ciliates imported into Traunsee } \\
\text { d Description in prep. }\end{array}$ & 2) & & $\mathrm{R}$ & & & & & & & & & & & & \\
\hline
\end{tabular}



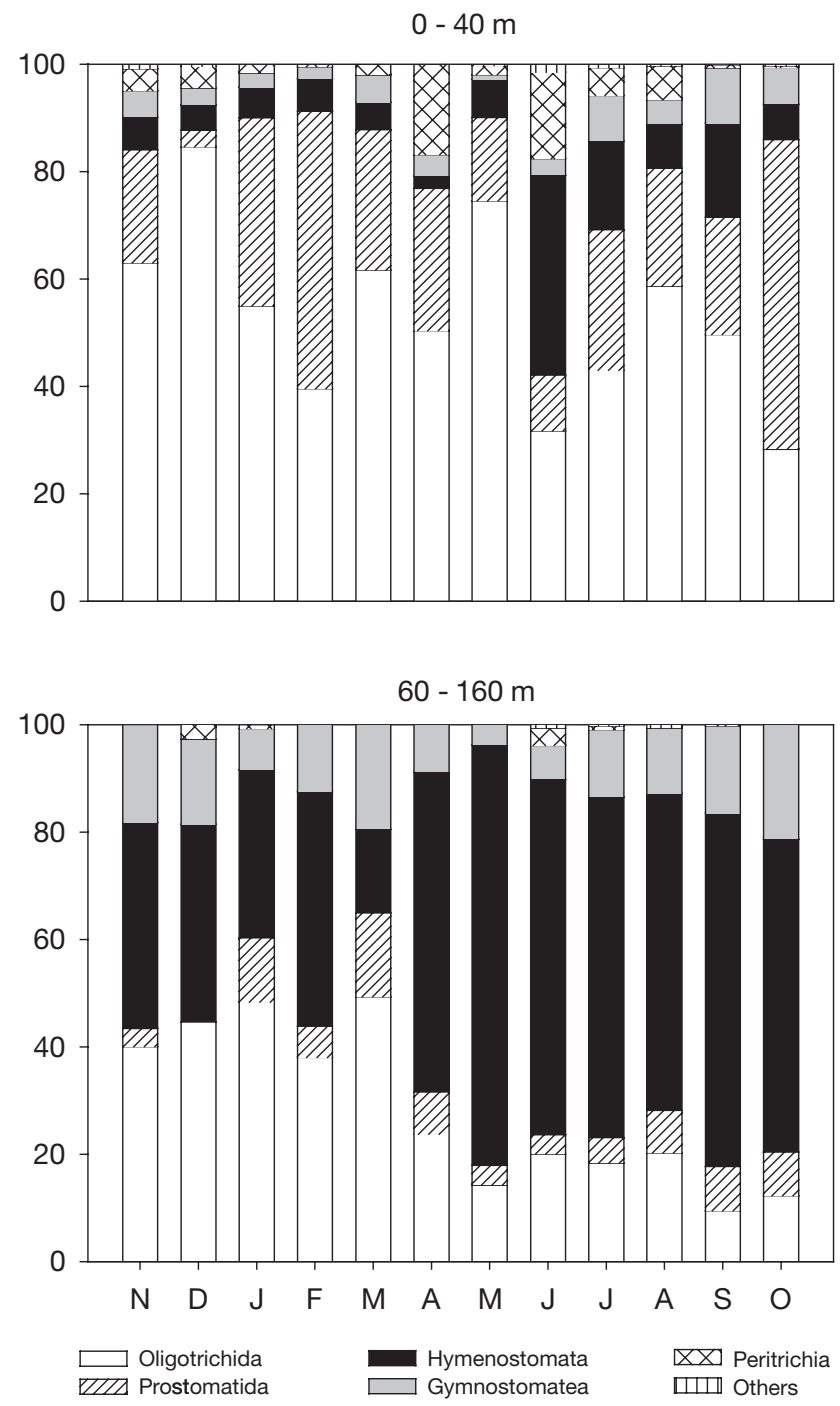

Fig. 3. Monthly percentages of the different ciliate groups at VI integrated over depths from 0 to $40 \mathrm{~m}$ (representative also for $\mathrm{EB}$ and $\mathrm{RB}$ ) and from 60 to $160 \mathrm{~m}$, respectively

The most remarkable change in the ciliate species composition along depths was found below both the euphotic and the mixing depth, i.e. between 20 and $40 \mathrm{~m}$ and 40 and $60 \mathrm{~m}$, respectively (Figs. 1A \& 2B). Changes in the ciliate assemblage structure were more persistent along depths than during seasons at all 3 sites (Fig. 2C). In particular, the persistence along depths was significantly higher at VI and EB than at RB. The more detailed similarity analysis by NMS showed that changes between months were less gradual, i.e. the relationship between the total abundance of ciliates and changes in the assemblage structure during seasons explained $66 \%$ of the similarity (Fig. 4A), along depths, $83 \%$ (Fig. 4F). The high percentage of algivorous ciliates explains the close
Table 3. Correspondence between environmental parameters and the ciliate assemblage structure changing with seasons and depths. The assemblage structure is summarised by scores of the first and second axis of NMS. The community structure along seasons and depths is summarised by scores of the first and second axis of NMS, respectively. (A) Relationship between environmental data and scores of the NMS axis (Pearson correlation coefficients) (DOC: dissolved organic carbon; TP: total phosphorus; $\mathrm{O}_{2}$ : oxygen). (B) Spearman rank order correlation between NMS axis and seasons, sites and depths (codes in brackets). Scores are displayed in Figs. 2E \& 4A, F

\begin{tabular}{|c|c|c|}
\hline & $\begin{array}{l}\text { NMS Axis } 1 \\
\text { (indicating } \\
\text { nainly seasons) }\end{array}$ & $\begin{array}{c}\text { NMS Axis } 2 \\
\text { (indicating } \\
\text { mainly depths }\end{array}$ \\
\hline \multicolumn{3}{|l|}{ (A) } \\
\hline Temperature & $-0.67^{* *}$ & $0.68^{* *}$ \\
\hline DOC & ns & $0.55^{* *}$ \\
\hline $\mathrm{TP}$ & ns & $0.42^{* *}$ \\
\hline $\mathrm{O}_{2}$ & ns & $0.35^{* *}$ \\
\hline Conductivity & ns & $-0.56^{* *}$ \\
\hline Chloride & $0.33^{*}$ & $-0.66^{* *}$ \\
\hline \multicolumn{3}{|l|}{ (B) } \\
\hline $\begin{array}{l}\text { Sites (coded as: } \\
\quad 1=\mathrm{VI}, 2=\mathrm{EB}, 3=\mathrm{RB})\end{array}$ & ns & $0.37^{* *}$ \\
\hline $\begin{array}{l}\text { Seasons (coded as: } \\
\quad 1=\text { winter, } 2 \text { = spring, } \\
3=\text { summer, } 4 \text { = autumn) }\end{array}$ & $-0.67^{* *}$ & ns \\
\hline $\begin{array}{l}\text { Depths (coded with } \\
\text { increasing numbers: } 0,10 \text {, } \\
20,40,60,80,120,160 \mathrm{~m} \text { ) }\end{array}$ & $0.34^{* *}$ & $-0.85^{* *}$ \\
\hline
\end{tabular}

relationship to changes in the total ciliate assemblage along depths (Fig. 4G). Mixotrophic ciliates followed the trend of algivorous ones (Fig. 4G). Both guilds were most numerous in the surface layers of Traunsee, decreasing with depth. Omnivorous ciliates followed the same vertical trend, however not significantly, and bacterivorous ciliates were inversely related to depth and increasingly important at deeper layers (Fig. 4H).

In the following, we describe in detail the pronounced changes of the ciliate assemblage structure during the 4 seasons in a functional model based on the mean annual abundance of the different nutritional modes in the top $20 \mathrm{~m}$ of the water column, as well as of the heterotrophic bacteria, phagotrophic flagellates and chl a (Fig. 5A,B). In addition, the relative contributions of the different nutritional modes are given according to season (Fig. 5C).

\section{Seasonal succession of free-living ciliates and functional guilds}

The seasonal succession of the whole ciliate assemblage was significantly related to the seasonal abun- 


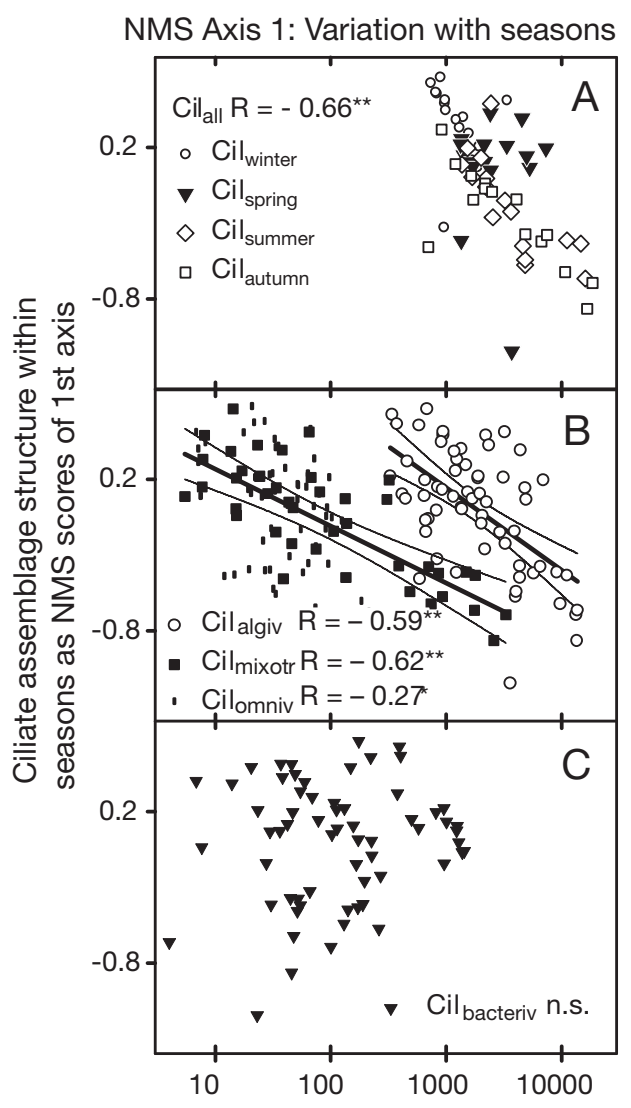

Abundance of ciliates (ind. $\left.\right|^{-1}$ )

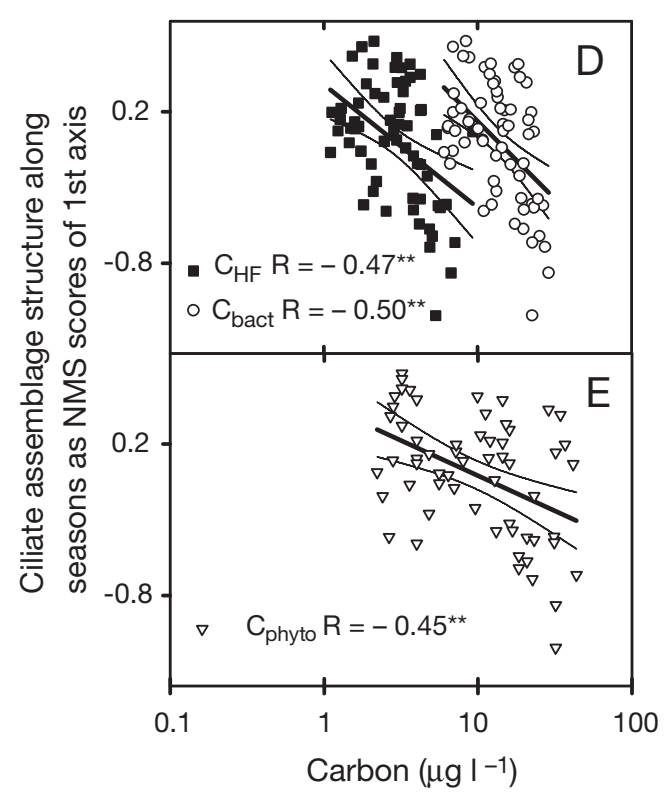

NMS Axis 2: Variation along depth gradient
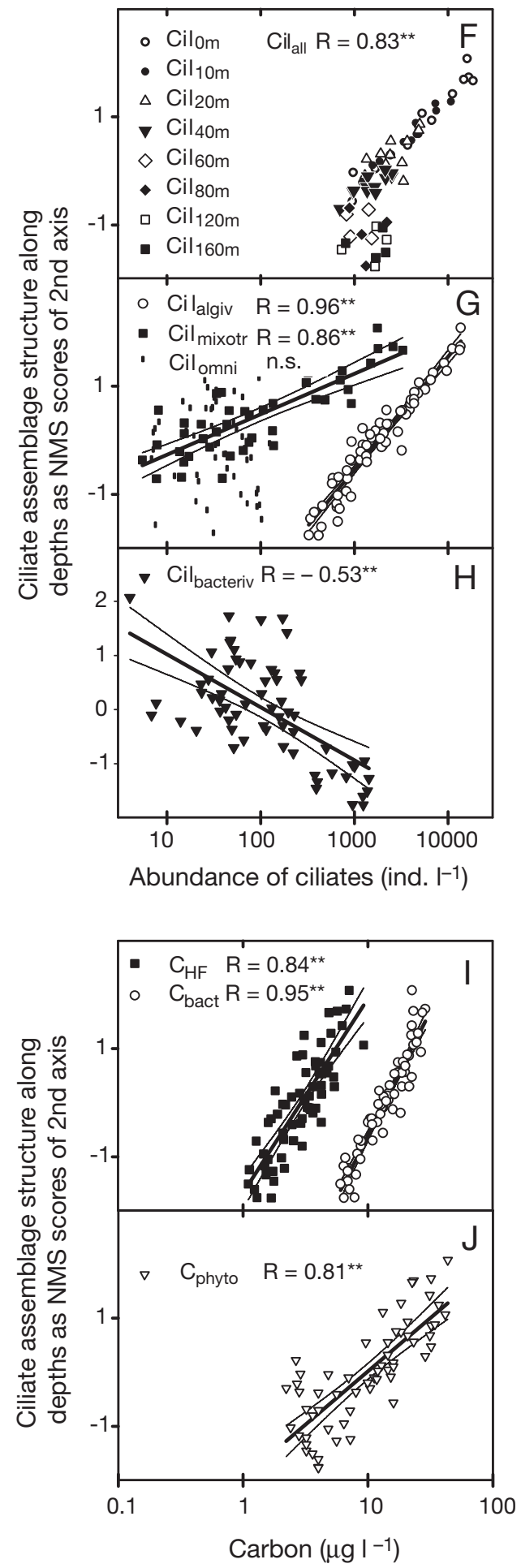

Fig. 4. Summary of the ciliate assemblage structure over seasons (scores of the first NMS axis, left panels) and depths (scores of the second NMS axis, right panels) related to the functional guilds of phagotrophic ciliates and flagellates, and bacteria and algae. Label overlay for seasons is shown in Panel A; for depths, in Panel F. Scores of the first NMS axis are most closely related to seasons; of the second axis, to depths (Spearman rank correlation coefficients and codes as in Table 3B). Relationship between NMS scores and abundance of total ciliates $(A, F)$; algivorous, mixotrophic and omnivorous ciliates (B, G); bacterivorous ciliates $(\mathrm{C}, \mathrm{H})$; the carbon of phagotrophic flagellates and heterotrophic bacteria $(\mathrm{D}, \mathrm{I})$; and the carbon of phytoplankton $(\mathrm{E}, \mathrm{J})$ are shown. Pearson correlation coefficients are given $\left({ }^{*} \mathrm{p}<0.05 ;{ }^{* *} \mathrm{p}<0.01\right.$; ns: not significant $)$ 

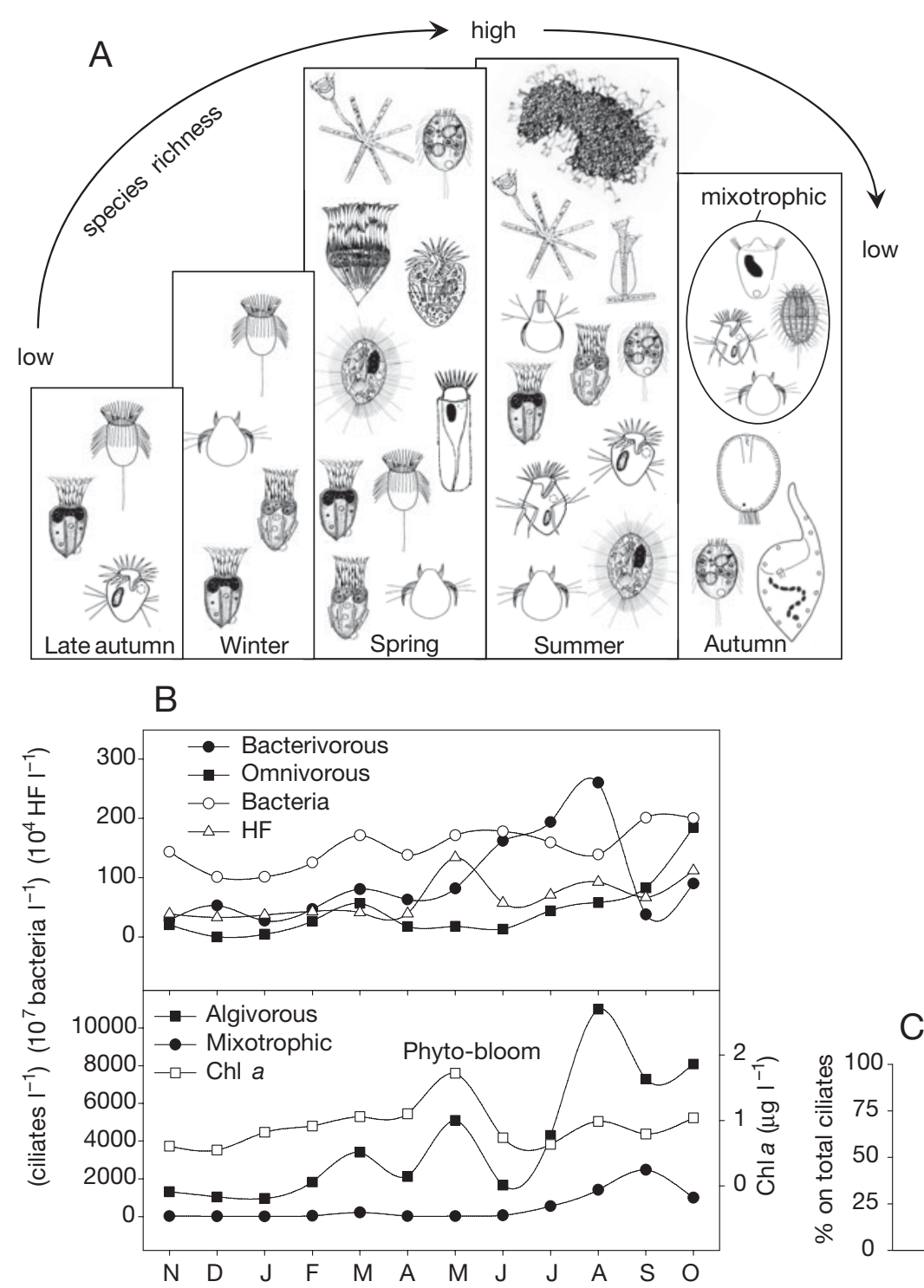
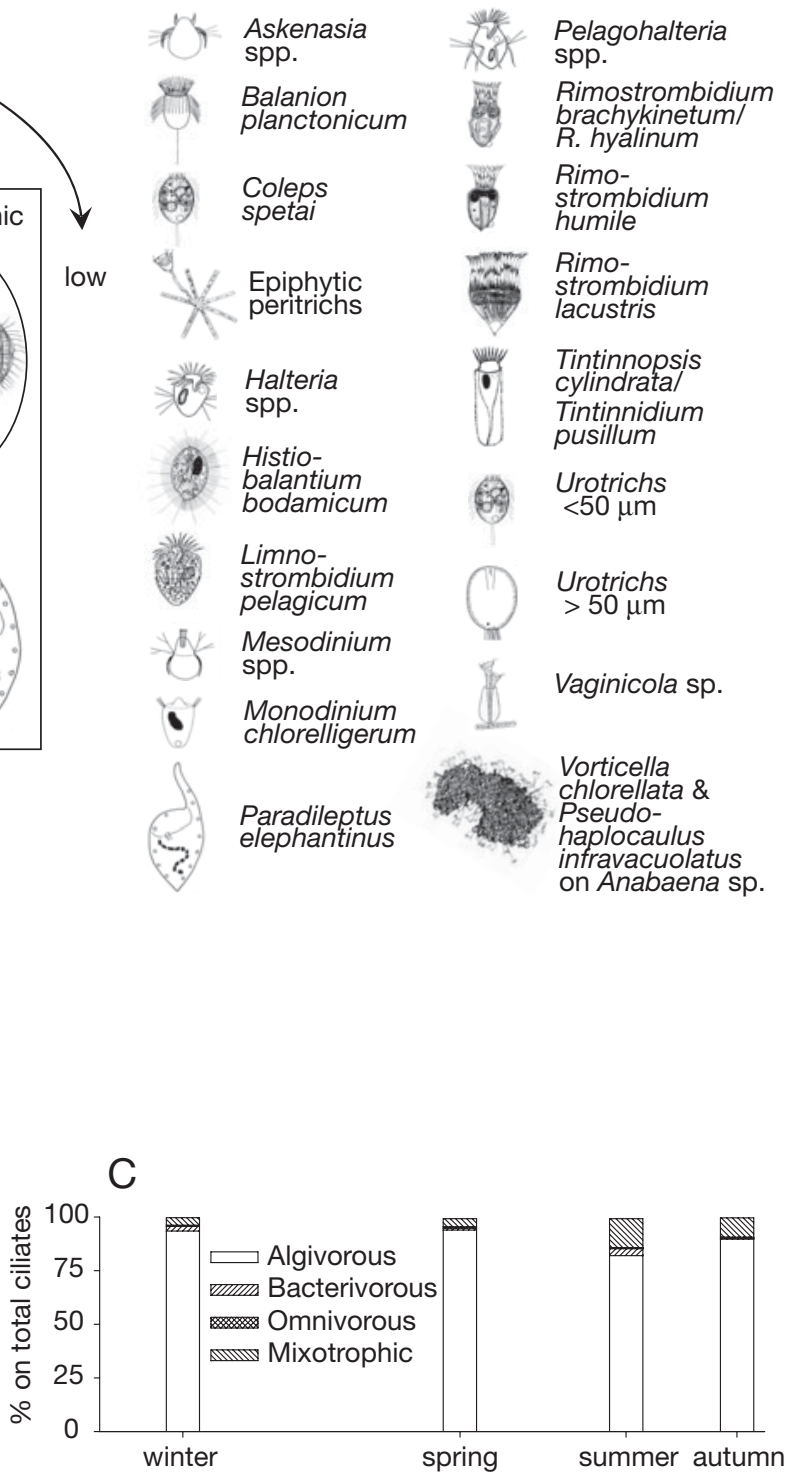

Fig. 5. Seasonal development of the ciliate assemblage for the upper 0 to $20 \mathrm{~m}$. (A) Scheme of species richness with the dominant ciliate taxa shown (drawings from Foissner et al. 1999). (B) Mean monthly abundance of ciliates attributed to different nutritional modes (see 'Materials and methods'), phagotrophic flagellates (HF), heterotrophic bacteria and chlorophyll a (chl a). (C) Relative contribution of ciliate nutritional modes by season

dance of algivorous, mixotrophic and omnivorous ciliates and their potential food sources (Fig. 4B,D \& E, respectively). Bacterivorous ciliates, however, were evenly distributed throughout seasons (Fig. 4C). Except for temperature and chloride concentration, the seasonal ciliate assemblage was not predictable by other environmental parameters (NMS Axis 1; Table 3A). The stability of the ciliate 'standing crop' was evaluated by the net change of the abundance (Fig. 2D). At all depth layers, $>80 \%$ similarity in the ciliate assemblage between successive monthly samples was found associated with almost zero net changes of total biovolume. Conversely, a strong increase or decrease in the abundance of ciliates was associated with pronounced changes in the species composition (similarity $<50 \%$ between successive samples; Fig. 2A).

\section{Winter}

In winter (November to February) and during holomixis, only a few ciliate species were found, and these in low numbers, due to the poor nutrient situation and low temperatures (Figs. 1A \& 5A,B, Table 2). In Decem- 
Table 4. Stepwise multiple linear regression (MLR) for the control of multiple food resources (carbon) of ciliates and phagotrophic flagellates $\left(\mathrm{R}^{2}\right.$ : squared correlation coefficient of $\mathrm{MLP}$; coeff.: unstandardised coefficient $\left[{ }^{*} \mathrm{p}<0.05,{ }^{*} \mathrm{p}<0.01\right.$, n.s: not significant]; SE: standard error of unstandardised coefficient; beta: standardised coefficient; algiv.: algivorous; bacteriv.: bacterivorous; mixotr.: mixotrophic; omniv.: omnivorous; HF: carbon of phagotrophic flagellates; na: not applicable)

\begin{tabular}{|c|c|c|c|c|c|c|c|c|c|c|c|}
\hline \multirow{2}{*}{\multicolumn{2}{|c|}{$\begin{array}{l}\text { Dependent } \\
\text { variable }\end{array}$}} & \multirow{2}{*}{\multicolumn{2}{|c|}{$\begin{array}{c}\text { Carbon from } \\
\text { heterotrophic } \\
\text { bacteria }\end{array}$}} & \multirow{2}{*}{\multicolumn{2}{|c|}{$\begin{array}{l}\text { Carbon from } \\
\text { phagotrophic } \\
\text { flagellates }\end{array}$}} & \multirow{2}{*}{\multicolumn{2}{|c|}{$\begin{array}{l}\text { - Independent var } \\
\text { Carbon from } \\
\text { chlorophyll } \\
\text { (fraction }<11 \mu \mathrm{m} \text { ) }\end{array}$}} & \multirow{2}{*}{\multicolumn{2}{|c|}{$\begin{array}{l}\text { ble entered } \\
\text { Carbon from } \\
\text { chlorophyll } \\
\text { (fraction } 11-33 \mu \mathrm{m} \text { ) }\end{array}$}} & \multirow[b]{2}{*}{$\begin{array}{l}\text { Carbon from } \\
\text { chlorophyll } \\
\text { (fraction }>33 \mu \mathrm{m} \text { ) }\end{array}$} & \multirow[b]{2}{*}{ Constan } \\
\hline & & & & & & & & & & & \\
\hline Group & $\mathrm{R}^{2}$ & $\begin{array}{l}\text { Coeff. } \\
\text { (SE) }\end{array}$ & Beta & $\begin{array}{l}\text { Coeff. } \\
\text { (SE) }\end{array}$ & Beta & $\begin{array}{l}\text { Coeff. } \\
\text { (SE) }\end{array}$ & Beta & $\begin{array}{l}\text { Coeff. } \\
\text { (SE) }\end{array}$ & Beta & $\begin{array}{l}\text { Coeff. Beta } \\
\text { (SE) }\end{array}$ & $\begin{array}{l}\text { Coeff. } \\
\text { (SE) }\end{array}$ \\
\hline $\begin{array}{l}\text { Total } \\
\text { ciliates }\end{array}$ & 0.80 & $\begin{array}{l}0.51^{*} \\
(0.22)\end{array}$ & 0.25 & ns & & ns & & $\begin{array}{l}1.17^{* *} \\
(0.19)\end{array}$ & 0.63 & ns & $\begin{array}{l}5.62^{* *} \\
(0.49)\end{array}$ \\
\hline $\begin{array}{l}\text { Algiv. } \\
\text { ciliates }\end{array}$ & 0.97 & $\begin{array}{l}1.59^{* *} \\
(0.15)\end{array}$ & 0.65 & ns & & ns & & $\begin{array}{l}0.76^{* *} \\
(0.13)\end{array}$ & 0.36 & ns & $\begin{array}{l}2.72^{* *} \\
(0.34)\end{array}$ \\
\hline $\begin{array}{l}\text { Bacteriv. } \\
\text { ciliates }\end{array}$ & 0.80 & $\begin{array}{c}-3.49^{* *} \\
(0.53)\end{array}$ & -1.09 & ns & & $\begin{array}{l}-0.72^{* *} \\
(0.27)\end{array}$ & -0.39 & $\begin{array}{l}2.65^{* *} \\
(0.42)\end{array}$ & 0.96 & ns & $\begin{array}{l}13.43^{* *} \\
(1.09)\end{array}$ \\
\hline $\begin{array}{l}\text { Mixotr. } \\
\text { ciliates }\end{array}$ & 0.83 & ns & & $\begin{array}{l}2.50^{*} \\
(1.12)\end{array}$ & 0.40 & ns & & $\begin{array}{l}2.12^{*} \\
(0.80)\end{array}$ & 0.47 & ns & $\mathrm{ns}$ \\
\hline $\begin{array}{l}\text { Omniv. } \\
\text { ciliates }\end{array}$ & 0.26 & ns & & ns & & ns & & $\begin{array}{c}0.70^{*} \\
(0.35)\end{array}$ & 0.26 & ns & $\begin{array}{l}2.82^{* *} \\
(0.30)\end{array}$ \\
\hline $\mathrm{HF}$ & 0.87 & $\begin{array}{l}0.58^{* *} \\
(0.09)\end{array}$ & 0.70 & na & na & $\begin{array}{l}0.10^{*} \\
(0.05)\end{array}$ & 0.21 & ns & ns & ns & $\begin{array}{c}-0.48^{*} \\
(0.18)\end{array}$ \\
\hline
\end{tabular}

ber $1997,>80 \%$ of the ciliates were represented by oligotrichs, i.e. Pelagohalteria cirrifera and Rimostrombidium spp. (Figs. $3 \& 5 \mathrm{~A}, \mathrm{~B}$ ). Towards the end of the winter, predominantly algivorous raptorial and filter feeders, such as Balanion planctonicum, Rimostrombidium spp., P. cirrifera and Rhabdoaskenasia minima, increased in abundance parallel to the development of chl a. In March, we noticed an exceptional peak of mainly algivorous and omnivorous ciliates at VI at depths of 10 to $20 \mathrm{~m}$, presumably influenced by nutrient inputs by the Traun River during spring snowmelt. Correspondingly, peaks in picocyanobacteria, centric and pennate diatoms and cryptophytes were observed (data not shown). B. planctonicum, Rimostrombidium spp., P. cirrifera, Mesodinium sp. and Urotricha spp. responded numerically to this increase in food, even at temperatures of 4 to $5^{\circ} \mathrm{C}$. The food vacuoles of, e.g., $R i$ mostrombidium lacustris or $R$. humile were densely packed with centric diatoms. Müller and co-workers (Müller 1989, Müller et al. 1991b, Müller \& Schlegel 1999) observed that the spring assemblage of Lake Constance (mainly B. planctonicum and Rimostrombidium spp.) was closely related to food resources and able to respond rapidly to a bloom of small phytoplankton.

\section{Spring}

In spring (March to May), algivorous and omnivorous ciliates, namely Balanion planctonicum, Rimostrombidium spp., Urotricha spp., Tintinnopsis cylindrata, Pelagohalteria cirrifera, Limnostrombidium pelagicum and Histiobalantium bodamicum appeared during the phytoplankton bloom and the chl a maximum (Fig. 5A,B, Table 2). At this time of the year, ciliates might be strong competitors with metazoan organisms, due to low generation times; hence, ciliates like B. planctonicum were assumed to be important contributors to the beginning of the so-called clearwater phase in meso- to eutrophic lakes, in addition to rotifers and other ciliates (Sommaruga \& Psenner 1993, 1995). Generally, they were among the first grazers of algal biomass in spring, with a preference for cryptophytes (Carrick \& Fahnenstiel 1989, Müller et al. 1991b, Müller \& Schlegel 1999).

\section{Summer}

At the onset of the stratification from May to June (Fig. 1A), ciliate and phytoplankton abundance decreased (Fig. 5B). Concurrently, the ciliate species composition changed abruptly (low similarity of $55 \%$ for May to June; Figs. 2A \& 5B). In June and July, prostomatids, hymenostomatids and peritrichs appeared in low numbers (Table 2). Predation by copepods and cladocerans might have been the reason for low total ciliate abundance during these months (Müller 1989, Stockner \& Shortreed 1989, Carrick et al. 1991, Müller et al. 1991a, Laybourn-Parry \& Rogerson 1993, Laybourn-Parry 1994, Jersabek pers. comm.). Free-living ciliates, namely Pelagohalteria viridis, halteriids and rimostrombidiids were most likely able to resist grazing pressure by their jumping behaviour (Gilbert 1994, 
review of Jürgens 1994, Wickham 1995). In contrast, epiphytic ciliates gained an advantage by their attachment to diatom colonies, thus becoming inedible for zooplankton predators (Carrias et al. 1998b, detailed discussion see below). Most likely, Balanion planctonicum was outcompeted in June by other algivorous ciliates like Histiobalantium bodamicum and haptorids (Askenasia volvox/Askenasia acrostomia, Rhabdoaskenasia minima, Mesodinium spp.) or grazed, e.g., by rotifers like Keratella cochlearis (Weisse \& Frahm 2002). Then again $B$. planctonicum increased in abundance in July and had its maximum in autumn. These findings are similar to those of Müller et al. (1991b) recorded from Lake Constance. Further, the scuticociliate $H$. bodamicum has been described as a 'superior competitor at relatively low algal food concentrations' (Müller \& Weisse 1994), which might explain its constantly rising mean abundance from May through September.

\section{Late summer and autumn}

Throughout the summer months the number of coexisting species increased (Fig. 5A,B, Table 2). From August through October, a heterogeneous assemblage including many mixotrophic species appeared. The abundance of the zoochlorella-bearing species, e.g. Pelagohalteria viridis, Monodinium chlorelligerum, Coleps spetai and Askenasia chlorelligera, increased in surface layers of Traunsee to a maximum of about 9000 cells $1^{-1}$ in September, which accounted for $25 \%$ of the total ciliate abundance at this time. Mixotrophic ciliates can reach up to $53 \%$ of the total abundance at certain times (Carrias et al. 1998a). Ciliates containing symbiotic algae are known to accumulate either in clear surface waters or near the oxycline (Hecky \& Kling 1981, Pace 1982, Berninger et al. 1986, Müller et al. 1991a, Carrias et al. 1998a). Mixotrophy, in general, is often considered as an adaptation permitting exploitation of food-poor oligotrophic environments, but serves a variety of purposes (Dolan \& Pérez 2000). The diversity of ciliates and food availability further increased in autumn, and the relationships between these 2 parameters became less clear, as various environmental factors might have enhanced the species diversity at this time (Müller et al. 1991a). At the end of the autumnal ciliate peak in Traunsee, large-sized predators, i.e. Urotricha venatrix and Paradileptus elephantinus, appeared and even had rotifers in their food vacuoles. However, bacterivorous and predatory ciliates seemed to be of minor importance when they occurred in summer and late autumn, as algivorous and omnivorous species were able to ingest around $43 \%$ of the primary production per year in Lake Constance (Müller et al. 1991a, Straile 1995).

\section{Epiphytic ciliates}

Sessile, bacterivorous peritrich ciliates appeared along with the occurrence of colonial algae, their preferred attachment sites, i.e. Vorticella vernalis on Fragilaria crotonensis and $V$. ingenita on Tabellaria fenestrata and Dinobryon spp. (Table 2). We observed their highest abundance in April, with $V$. vernalis as the dominant species. In autumn, this ciliate species appeared again together with $V$. ingenita. In August, the epiphytic Pseudohaplocaulus infravacuolatus was associated with Vorticella chlorellata, both attached to the chain-like colonies of the cyanobacterium Anabaena lemmermannii. Ruttner (1937) previously described the occurrence of 2 vorticellids on Anabaena flos-aquae in Traunsee, and Carrias et al. (1998a) found this association in Lake Pavin. However, in the meantime, A. flos-aquae has disappeared from Traunsee, indicating a shift to more oligotrophic conditions. Hunt \& Chein (1983 and references therein) described vorticellids attached to Anabaena colonies as typical members of the ciliate assemblage of the Great Lakes. In general, epibiotic ciliates and flagellates have a major grazing impact on free bacteria, even when they are present in low numbers (Carrias et al. 1996). The attachment of peritrichs to colonial algae apparently provides a refuge from potential grazers, as they are too bulky to be ingested by zooplankton (Carrick et al. 1991, Carrias et al. 1996).

\section{Seasonal succession of free-living phagotrophic flagellates}

The seasonal dynamics of phagotrophic flagellates (HF) showed 2 peaks, one during the phytoplankton bloom in spring and another in autumn (Figs. 1B \& 5B). Abundance and biovolume in the top $40 \mathrm{~m}$ were not significantly different between EB, RB and VI (Fig. 1B). Taxa $<5 \mu \mathrm{m}$ in length (fixed) accounted for 88 to $90 \%$ of total $\mathrm{HF}$ at depths from 0 to $40 \mathrm{~m}$ and $82 \%$ from 60 to $160 \mathrm{~m}$ (Sonntag et al. 2002). Those small HF were represented primarily by Monas-like cells and a so far unidentified HF with a decentral nucleus. An unidentified $\mathrm{HF}>5 \mu \mathrm{m}$ with a kinetoplast increased numerically with depth. Kathablepharis sp., another HF $>5 \mu \mathrm{m}$ assumed to be mixotrophic, was also present at low densities. In total, numbers of HF in Traunsee were within the range reported for oligo- to mesotrophic water bodies (e.g. Carrias et al. 1998b, Sonntag et al. 2002), i.e. between 40 and $2900 \mathrm{ml}^{-1}$ for the present study.

The flagellate assemblage structure changed during the transition from the phytoplankton spring bloom to summer, with small HF such as heterokonts and epiphytic flagellates becoming increasingly abundant, as 
already reported for Lake Constance (Cleven \& Weisse 2001). The time of the phytoplankton bloom was also the time of the highest bacterial numbers (Table 2). Free-living HF in Traunsee were significantly correlated to ciliates (Fig. 4D) and heterotrophic bacteria in the top $40 \mathrm{~m}$ (Table 4). Small heterotrophic flagellates, e.g. Spumella spp., are known to be efficient bacterivores, able to consume around half of the bacterial production (Weisse 1990, 1991, Simon et al. 1998). A coincidence of bacterial and HF densities and the predominance of $\mathrm{HF}<5 \mu \mathrm{m}$ in length has already been reported for Lake Constance (Weisse 1990, 1991, Cleven \& Weisse 2001), Mondsee (Salbrechter \& Arndt 1994) and Lake Pavin (Carrias et al. 1998b). However, the relationship between HF and bacteria seems to be stronger in systems with low bacterial abundance compared to systems with higher bacterial numbers (Gasol \& Vaqué 1993).

\section{Epiphytic flagellates}

Sessile flagellates were present in the whole water column (0 to $160 \mathrm{~m}$ depth) from May through October, appearing along with the occurrence of suitable attachment sites, i.e. colonial diatoms. They accounted for up to $7 \%$ of total HF in Traunsee and 9 to $11 \%$ in Lake Pavin (Carrias et al. 1996, 1998b). In Traunsee, epiphytic flagellates were mainly represented by a choanoflagellate of the genus Salpingoeca (for taxonomic considerations see Sonntag et al. 2000) attached to the diatom Asterionella formosa, and an unidentified epiphytic flagellate on the diatom Fragilaria crotonensis. In May, Salpingoeca sp. accounted for around $50 \%$ of total epiphytic flagellates; from June through August, an unidentified morphotype dominated the sessile assemblage. Then, Salpingoeca sp. again increased numerically in September and October, accounting for $\sim 100 \%$ of epiphytic flagellate abundance. However, its occurrence was not restricted to late summer and autumn as previously described (Weisse et al. 1995, Cleven \& Weisse 2001, Auer \& Arndt 2002). Šimek et al. (2004) observed that at certain times Salpingoeca sp. is the most important bacterivorous species in the plankton.

\section{CONCLUSIONS}

Here, we showed that phagotrophic ciliates assigned to at least 4 different guilds and flagellates are important members of the planktonic food web in a cold, deep, oligotrophic lake, an environment previously thought to be unfit for many protists. Although present in low numbers, our data on the seasonal and vertical distribution demonstrate that the phagotrophic protists occupy a number of different ecological niches at various trophic levels (primary and secondary consumers). High taxonomic resolution was a prerequisite to interpret the findings precisely, and we would like to encourage researchers to use the high-standard methods available, especially for ciliate identification, e.g. QPS instead of Lugol's solution.

We assessed the strength of predictive relationships structuring the ciliate assemblage along the depth gradient by parameters of the bottom-up control cascade, i.e. by nutrients (phosphorus, DOC) and food sources from algae to bacteria and flagellates. Hence, the coherent correlation pattern of food and environmental variables predicting changes in the ciliate assemblage structure clearly mediated bottom-up cascades through the food web. The seasonal succession in the ciliate assemblage was also significant, but less predictable by food-source parameters in contrast to its depth distribution. Hence, the seasonal changes in the ciliate structure were not primarily mediated by bottom-up control. We assume that seasonal community structure in Traunsee was also driven by effects of the top-down control not studied.

Acknowledgements. We thank C. Griebler and B. Mindl for cooperation, discussions and logistics; K. Maier for technical support in the field; and C. Jersabek for the contribution of unpublished data on zooplankton. Comments by H. Müller, $\mathrm{H}$. Zimmermann-Timm and T. Weisse on an earlier version and by 3 anonymous reviewers are gratefully acknowledged. The project was funded by the Government of Upper Austria (contract with the Austrian Academy of Sciences).

\section{LITERATURE CITED}

APHA (American Public Health Association) (1992) Standard methods for the examination of water and wastewater, 18th edn. APHA, Washington, DC

Auer B, Arndt H (2002) Taxonomic composition and biomass of heterotrophic flagellates in relation to lake trophy and season. Freshw Biol 46:959-972

Azam FT, Fenchel T, Field JG, Gray JS, Meyer-Reil LA, Thingstad F (1983) The ecological role of water-column microbes in the sea. Mar Ecol Prog Ser 10:257-263

Beaver JR, Crisman TL (1989) The role of ciliated protozoa in pelagic freshwater ecosystems. Microb Ecol 17: $111-136$

Berninger UG, Finlay BJ, Canter HM (1986) The spatial distribution and ecology of zoochlorellae-bearing ciliates in a productive pond. J Protozool 33:557-563

Carrias JF, Amblard C, Bourdier G (1996) Protistan bacterivory in an oligomesotrophic lake: importance of attached ciliates and flagellates. Microb Ecol 31:249-268

Carrias JF, Amblard C, Bourdier G (1998a) Seasonal dynamics and vertical distribution of planktonic ciliates and their relationship to microbial food resources in the oligomesotrophic Lake Pavin. Arch Hydrobiol 143:227-255

Carrias JF, Amblard C, Quiblier-Lloberas C, Bourdier G (1998b) Seasonal dynamics of free and attached hetero- 
trophic nanoflagellates in an oligomesotrophic lake. Freshw Biol 39:91-101

Carrick HJ, Fahnenstiel GL (1989) Biomass, size structure, and composition of phototrophic and heterotrophic nanoflagellate communities in Lakes Huron and Michigan. Can J Fish Aquat Sci 46:1922-1928

Carrick HJ, Fahnenstiel GL, Stoermer EF, Wetzel RG (1991) The importance of zooplankton-protozoan trophic couplings in Lake Michigan. Limnol Oceanogr 36:1335-1345

Clarke KR (1993) Non-parametric multivariate analyses of changes in community structure. Aust J Ecol 18:117-143

Cleven EJ, Weisse T (2001) Seasonal succession and taxon-specific bacterial grazing rates of heterotrophic nanoflagellates in Lake Constance. Aquat Microb Ecol 23:147-161

Dolan JR, Pérez MT (2000) Costs, benefits and characteristics of mixotrophy in marine oligotrichs. Freshw Biol 45: 227-238

Félip M, Bartumeus F, Halac S, Catalan J (1999) Microbial plankton assemblages, composition and biomass, during two ice-free periods in a deep high mountain lake (Estany Redó, Pyrenees). In: Straskrabová V, Callieri C, Fott J (eds) Pelagic food webs in mountain lakes. Mountain Lakes Research Program. J Limnol 58:193-202

Foissner W, Blatterer H, Berger H, Kohmann F (1991) Taxonomische und ökologische Revision der Ciliaten des Saprobiensystems, Band I: Cyrtophorida, Oligotrichida, Hypotrichia, Colpodea. Informationsbericht 1/91, Bayer. Landesamtes für Wasserwirtschaft, Munich, p 1-478

Foissner W, Berger H, Kohmann F (1992) Taxonomische und ökologische Revision der Ciliaten des Saprobiensystems, Band II: Peritrichia, Heterotrichida, Odontostomatida. Informationsbericht 5/92, Bayer. Landesamtes für Wasserwirtschaft, Munich, p 1-502

Foissner W, Berger H, Kohmann F (1994) Taxonomische und ökologische Revision der Ciliaten des Saprobiensystems, Band III: Hymenostomata, Prostomatida, Nassulida. Informationsbericht 1/94, Bayer. Landesamtes für Wasserwirtschaft, Munich, p 1-548

Foissner W, Berger H, Blatterer H, Kohmann F (1995) Taxonomische und ökologische Revision der Ciliaten des Saprobiensystems, Band IV: Gymnostomatea, Loxodes, Suctoria. Informationsbericht 1/95, Bayer. Landesamtes für Wasserwirtschaft, Munich, p 1-540

Foissner W, Berger H, Schaumburg J (1999) Identification and ecology of limnetic plankton ciliates. Informationsbericht 3/99, Bayer. Landesamtes für Wasserwirtschaft, Munich, p 1-793

Gasol JM, Vaqué D (1993) Lack of coupling between heterotrophic nanoflagellates and bacteria: A general phenomenon across aquatic systems? Limnol Oceanogr 38:657-665

Gilbert JJ (1994) Jumping behaviour in the oligotrich ciliates Strobilidium velox and Halteria grandinella, and its significance as a defense against rotifer predators. Microb Ecol 27:189-200

Griebler C, Sonntag B, Mindl B, Posch T, Klammer S, Psenner R (2002) Assessment of the ecological integrity of Traunsee (Austria) via analysis of sediments and benthic microbial communities. Water Air Soil Pollut 2:33-62

Hecky RE, Kling HJ (1981) The phytoplankton and protozooplankton of the euphotic zone of Lake Tanganyika: species composition, biomass, chlorophyll content, and spatiotemporal distribution. Limnol Oceanogr 26:548-564

Hunt GW, Chein SM (1983) Seasonal distribution, composition and abundance of the planktonic Ciliata and Testacea of Cayuga Lake. Hydrobiologia 98:257-266

Jagsch A, Dokulil MT, Gassner H (2002) Long-term changes in environmental variables of Traunsee, an oligotrophic lake impacted by salt industry. Water Air Soil Pollut 2: 9-20

James MR, Burns CW, Forsyth DJ (1995) Ciliated protozoa in two monomictic, southern temperate lakes of contrasting trophic state: seasonal distribution and abundance. J Plankton Res 17:1479-1500

Jürgens K (1994) Impact of Daphnia on planktonic microbial food webs-A review. Mar Microb Food Webs 8:295-324

Klammer S, Posch T, Sonntag B, Griebler C, Mindl B, Psenner R (2002) Dynamics of bacterial abundance, biomass, activity, and community composition in the oligotrophic Traunsee and the Traun River (Austria). Water Air Soil Pollut 2: 137-163

Laybourn-Parry J (1994) Seasonal successions of protozooplankton in freshwater ecosystems of different latitudes. Mar Microb Food Webs 8:145-162

Laybourn-Parry J, Rogerson A (1993) Seasonal patterns of protozooplankton in Lake Windermere, England. Arch Hydrobiol 129:24-43

Menden-Deuer S, Lessard EJ (2000) Carbon to volume relationships for dinoflagellates, diatoms and other protist plankton. Limnol Oceanogr 45:569-579

Montagnes DJS, Lynn DH (1987) A quantitative protargol stain (QPS) for ciliates: method description and test of its quantitative nature. Mar Microb Food Webs 2:83-93

Müller H (1989) The relative importance of different ciliate taxa in the pelagic food web of Lake Constance. Microb Ecol 18:261-273

Müller H, Schlegel A (1999) Responses of three freshwater planktonic ciliates with different feeding modes to cryptophyte and diatom prey. Aquat Microb Ecol 17:49-60

Müller H, Weisse T (1994) Laboratory and field observations on the scuticociliate Histiobalantium from the pelagic zone of Lake Constance, FRG. J Plankton Res 16:391-401

Müller H, Schöne A, Pinto-Coelho RM, Schweizer A, Weisse $\mathrm{T}$ (1991a) Seasonal succession of ciliates in Lake Constance. Microb Ecol 21:119-138

Müller H, Geller W, Schöne A (1991b) Pelagic ciliates in Lake Constance: comparison of epilimnion and hypolimnion. Verh Int Verein Limnol 24:846-849

Müller J, Wallner J, Kroemer E (2002) Industrial tailings in Traunsee revisited-the status of 1999. Water Air Soil Pollut 2:21-32

Nakano S, Ishii N, Manage PM, Kawabata Z (1998) Trophic roles of heterotrophic nanoflagellates and ciliates among planktonic organisms in a hypertrophic pond. Aquat Microb Ecol 16:153-161

Pace ML (1982) Planktonic ciliates: their distribution, abundance, and relationship to microbial resources in a monomictic lake. Can J Fish Aquat Sci 39:1106-1116

Patterson DJ, Larsen J (1991) The biology of free-living heterotrophic flagellates. Clarendon Press, Oxford

Pechlaner R, Sossau C (1982) Die Ergebnisse der fünfjährigen Studie 'Limnologische Untersuchung Traunsee-Traun'. Limnologische Untersuchung Traunsee-Traun 13, Amt der Oberösterreichischen Landesregierung, Linz, p 1-100

Pfister G, Sonntag B, Posch T (1999) Comparison of a direct live count and an improved quantitative protargol stain (QPS) in determining abundance and cell volumes of pelagic freshwater protozoa. Aquat Microb Ecol 18:95-103

Pfister G, Auer B, Arndt H (2002) Pelagic ciliates (Protozoa, Ciliophora) of different brackish and freshwater lakes - a community analysis at the species level. Limnologica 32: $147-168$

Porter KG, Feig YS (1980) The use of DAPI for identifying and counting aquatic microflora. Limnol Oceanogr 25:943-948 
Ruttner F (1937) Limnologische Studien an einigen Seen der Ostalpen. Arch Hydrobiol Spec Iss Adv Limnol 32:167-319

Salbrechter M, Arndt H (1994) The annual cycle of protozooplankton in the alpine, mesotrophic lake Mondsee (Austria). Mar Microb Food Webs 8:217-234

Schmidt R, Dokulil MT, Psenner R, Wanzenboeck J (2002) Ecological integrity: concept, assessment, evaluation: the Traunsee case. Water Air Soil Pollut 2:249-261

Schweizer A (1994) Seasonal dynamics of Ciliophora along a transect in Lake Constance. Mar Microb Food Webs 8: 283-293

Sherr EB, Sherr BF (1993) Preservation and storage of samples for enumeration of heterotrophic protists. In: Kemp PF, Sherr BF, Sherr EB, Cole JJ (eds) Handbook of methods in aquatic microbial ecology. Lewis Publishers, London

Šimek K, Jürgens K, Nedoma J, Comerma M, Armengol J (2000) Ecological role and bacterial grazing of Halteria spp.: small freshwater oligotrichs as dominant pelagic ciliate bacterivores. Aquat Microb Ecol 22:43-56

Šimek K, Jezbera J, Horňák K, Vrba J, Sed'a J (2004) The role of diatom-attached choanoflagellates of the genus Salpingoeca as pelagic bacterivores. Aquat Microb Ecol 36: 257-269

Simon M, Tilzer MM, Müller H (1998) Bacterioplankton in a large mesotrophic lake. I. Abundance, production and growth control. Arch Hydrobiol 143:385-407

Skibbe O (1994) An improved quantitative protargol stain for ciliates and other planktonic protists. Arch Hydrobiol 130: 339-347

Sommaruga R, Psenner R (1993) Nanociliates of the order Prostomatida: their relevance in the microbial food web of a mesotrophic lake. Aquat Sci 55:179-187

Sommaruga R, Psenner R (1995) Trophic interactions within the microbial food web in Piburger See (Austria). Arch Hydrobiol 132:257-278

Sonntag B, Foissner W (2004) Urotricha psenneri n. sp. and Amphileptus piger (Vuxanovici, 1962) n. comb., two planktonic ciliates (Protozoa, Ciliophora) from an oligotrophic lake in Austria. J Eukaryot Microbiol 51:670-677

Sonntag B, Posch T, Psenner R (2000) Comparison of three methods for determining flagellate abundance, cell size, and biovolume in cultures and natural freshwater samples. Arch Hydrobiol 149:337-351

Sonntag B, Posch T, Klammer S, Griebler C, Psenner R (2002)

Editorial responsibility: John Dolan,

Villefranche-sur-Mer, France
Protozooplankton in the deep oligotrophic Traunsee (Austria) influenced by discharges of soda and salt industries. Water Air Soil Pollut 2:211-226

Stockner JG, Shortreed KS (1989) Algal picoplankton production and contribution to food-webs in oligotrophic British Columbia lakes. Hydrobiologia 173:151-166

Straile D (1995) Die saisonale Entwicklung des Kohlenstoffkreislaufes im pelagischen Nahrungsnetz des Bodensees-Eine Analyse von massenbilanzierten Flussdiagrammen mit Hilfe der Netzwerktheorie. PhD dissertation, Hartung Gorre, University of Konstanz

Taylor WD, Heynen ML (1987) Seasonal and vertical distribution of Ciliophora in Lake Ontario. Can J Fish Aquat Sci 44:2185-2191

Teubner K (2003) Phytoplankton, pelagic community and nutrients in a deep oligotrophic alpine lake: ratios as sensitive indicators of the use of P-resources (DRP:DOP:PP and TN:TP:SRSi). Water Res 37:1583-1592

Teubner K, Dokulil MT (2002) ${ }^{14} \mathrm{C}$-photosynthesis of phytoplankton in an oligotrophic alpine lake (Traunsee, Austria) and its response to turbidity caused by industrial tailings. Water Air Soil Pollut 2:181-190

Weisse $\mathrm{T}$ (1990) Trophic interactions among heterotrophic microplankton, nanoplankton, and bacteria in Lake Constance. Hydrobiologia 191:111-122

Weisse T (1991) The annual cycle of heterotrophic freshwater nanoflagellates: role of bottom-up versus top-down control. J Plankton Res 13:167-185

Weisse T, Frahm A (2002) Direct and indirect impact of two common rotifer species (Keratella spp.) on two abundant ciliate species (Urotricha furcata, Balanion planctonicum). Freshw Biol 47:53-64

Weisse T, Müller H (1998) Planktonic protozoa and the microbial food web in Lake Constance. Arch Hydrobiol Spec Issues 53:223-254

Weisse T, Springmann D, Müller H (1995) Ökologie des heterotrophen Nanoplanktons im Süßwasser und Meer. In: Röttger R (ed) Praktikum der Protozoologie. Fischer Verlag, Stuttgart, p 40-47

Wickham SA (1995) Cyclops predation on ciliate speciesspecific differences and functional responses. J Plankton Res 17:1633-1646

Wright SW, Jeffrey SW, Mantoura RFC, Llewellyn CA, Bjornland T, Repela D, Welschmeyer N (1991) Improved method for the analysis of chlorophylls and carotenoids from marine phytoplankton. Mar Ecol Prog Ser 77:183-196

Submitted: May 1, 2005; Accepted: December 16, 2005

Proofs received from author(s): May 23, 2006 